\title{
Genetics of Vascular Inflammation in Lower Limb Ischemia: The TNF- $\alpha$ Hypothesis in Peripheral Arterial Disease
}

\author{
Diego Caicedo ${ }^{1 *}$, Clara V. Álvarez ${ }^{2}$, Sihara Pérez ${ }^{2}$ and Jesús Devesa ${ }^{3}$
}

\author{
${ }^{1}$ Angiology and Vascular Surgery department. Complejo Hospitalario de Santiago de Compostela. Spain; \\ diego.caicedo.valdes@sergas.es \\ ${ }^{2}$ Neoplasia and Differentiation of Endocrine Cells group. Center for Research in Molecular Medicine and Chronic \\ Diseases (CIMUS). University of Santiago de Compostela. Spain; clara.alvarez@usc.es; siara.perez@usc.es. \\ ${ }^{3}$ The Medical Center Foltra. Teo. Spain \\ *Correspondence: diego.caicedo.valdes@sergas.es; +34 981950043
}

\begin{abstract}
:
Background: Vascular inflammation plays a crucial role in peripheral arterial disease (PAD), although the role of the mediators involved has not yet been properly defined. The aim of this work is to investigate gene expression and plasma biomarkers in chronic limb-threating ischemia (CLTI). Methods: Using patients from the GHAS trial, both blood and ischemic muscle samples were obtained to analyze plasma markers and mRNA expression, respectively. Statistical analysis was performed by using univariate (Spearman, t-Student, $\mathrm{X}^{2}$ ) and multivariate (multiple logistic regression) tests. Results: 35 patients were available at baseline (29 for mRNA expression). Baseline characteristics (mean): Age:71.4 \pm 12.4 (79.4\% male); TNF- $\alpha: 10.7 \pm 4.9$; hs-CRP:1.6 \pm 2.2 ; Neutrophil-to-lymphocyte ratio (NLR):3.5 \pm 2.8 . Plasma TNF- $\alpha$ was found elevated $(\geq 8.1)$ in $68.6 \%$ of patients, while high hs-CRP $(\geq 0.5)$ in $60.5 \%$. Diabetic patients with high level of inflammation showed significantly higher levels of NOX4 expression at baseline ( $\mathrm{p}=0.0346)$. Plasma TNF- $\alpha$ had a negative correlation with eNOS expression $(-0.5, \mathrm{p}=0.015)$ and hs-CRP with VEGF-A $(-0.63, \mathrm{p}=0.005)$. The expression of NOX4 was parallel to that of plasma TNF- $\alpha(0.305, \mathrm{p}=0.037)$, especially in DM. Cumulative mortality at 12 month was related to NLR $\geq 3(\mathrm{p}=0.019)$ and TNF- $\alpha \geq 8.1(\mathrm{p}=0.048)$. The best cut-off point for NLR to predict mortality was 3.4. Conclusions: NOX4 and TNF- $\alpha$ are crucial for the development and complications of lower limb ischemia, especially in DM. hs-CRP could have a negative influence on angiogenesis too. NLR and TNF- $\alpha$ represent suitable markers of mortality in CLTI. These results are novel because they connect muscle gene expression and plasma information in patients with advanced PAD, deepening the search of new and accurate targets for this condition.
\end{abstract}

Keywords: Vascular inflammation; Peripheral arterial disease (PAD); Chronic limb-threatening ischemia (CLTI); GHAS trial; TNF- $\alpha$; hs-CRP; Neutrophil-to-lymphocyte ratio (NLR); NOX4; eNOS; VEGF-A.

\section{Introduction}

Peripheral Arterial Disease (PAD) is an occlusive arterial disease, mainly of atherosclerotic origin, that affects lower limbs. It represents an independent risk factor for cardiovascular (CV) morbidity and mortality [1-3]. In fact, these patients have a CV event rate similar to those with established coronary or cerebral vascular disease [4-6]. Considering that there are few tools to identify who PAD patients are at risk for suffering an acute event, risk handling in this setting represents a major health challenge [4,7]. On the other hand, inflammation plays a key role in the development of PAD, but, 
unfortunately, the mediators involved in this condition have not yet been fully defined $[8,9]$. The isolated use of clinical staging of PAD (Rutherford class) ignores the importance of other factors that may also be crucial for long-term survival in these patients, such as biomarkers of systemic inflammation or endothelial dysfunction $[9,10]$.

From this perspective, some pro-inflammatory cytokines have been involved in the development and complication of atherosclerosis. Both experimental and large cohort studies in humans have evaluated the role of inflammatory cytokines [3,11-14]. IL-6, TNF$\alpha$ or C-reactive protein of high sensitivity (hs-CRP) have been found predictive of future $\mathrm{CV}$ events in healthy and diseased populations $[15,16]$. However, studies using Mendelian randomization have shown contradictory results depending on the marker $[9,15,17-19]$. This fact highlights the need to continue searching for and to differentiate between causal markers and acute phase reactants. In addition, it seems that different cytokines could influence different vascular beds in different ways. Moreover, murine and human data do not always coincide, as we will see below.

Inflammation has a clear deleterious effect on vessel endothelial function. Indeed, the CANTOS trial provided the first compelling evidence that inhibition of cytokine function, by decreasing the activity of IL- $1 ß$ and IL- 6 signaling pathways, can reduce CV risk regardless of blood pressure or lipid level [20]. But this breakthrough has only been demonstrated so far for coronary heart disease. In PAD, several cytokines have been associated with disease progression in one cohort study, finding a significant increase in the levels of IL-6, TNF- $\alpha$, selectins, neopterin, CAMs, MMP-2 or MMP-9 [21]. However, a preceding study found no significant difference for IL- 6 and IL-1ß in lower limbs ischemia [22]. While in the CANTOS study the relevant role is for IL-6, in PAD the levels of TNF- $\alpha$ and IL-8 were clearly increased, which supports the statement of different inflammatory patterns in both atherosclerotic conditions. Further, IL-6 secretion is highly dependent on TNF- $\alpha$ and appears to have different behavior when secreted by monocytes (proinflammatory) or skeletal muscle (anti-inflammatory) [23]. In addition, non-randomized observational studies have suggested a reduction in the rate of atherosclerotic events in patients treated with TNF- $\alpha$ inhibitors [24]. However, the causal association between these or other biomarkers and PAD has not yet been established.

Neutrophil-to-lymphocyte ratio (NLR), defined as the ratio between absolute count of neutrophils and lymphocytes, has been gaining relevance as a marker of CV disease. Many researchers have deeply evaluated NLR as a potential prognostic biomarker, predicting pathological and survival outcomes in patients with atherosclerosis, and, in particular, in PAD, in which a strong relationship has been identified for systemic (long-term mortality) and local (lower limb) complications [25].

It is also well known that oxidative stress also plays an important role in endothelial dysfunction in the inflammatory context of CV disease. Many studies have highlighted how oxidative distress triggers and impairs this condition, facilitating adverse $\mathrm{CV}$ events $[26,27]$. Although many studies currently address inflammation and redox balance in the vascular system, few of them have cross-linked gene and plasma information in a human trial.

Here we present new insights from an interventional study, the GHAS trial, in which information about muscle tissue mRNA expression and plasma biomarkers has been combined in patients suffering from chronic limb-threatening ischemia (CLTI). Our results are novel because they were obtained in this PAD special subset of patients presenting CLTI, who represent those with the highest level of inflammation and CV risk.

\section{Materials and Methods}

From January 2016 to December 2018, all patients with diagnosis of CLTI who met inclusion criteria were enrolled in the Growth Hormone Angiogenic Study (GHAS) trial. The GHAS study, a phase III randomized controlled trial, was designed to test the benefit of low dose of GH for wound healing and rest pain relief in CLTI [27-29]. Blood samples were extracted for the determination of plasma biomarkers at the beginning of the study (basal) and after two months of treatment initiation (final). Skeletal muscle samples from the ischemic limb were also obtained with the same time interval. 


\subsection{Informed Consent and Recruitment}

Written informed consent was obtained from each participant at the beginning of the investigation. The recruitment of the subjects for this study was made by vascular surgeons in the Angiology and Vascular Surgery department of the Clinical Hospital of Pontevedra, Spain. The GHAS trial counted with the registration in the Spanish Registry of Clinical Trials (REEC) with the number: 2012-002228-34.

\subsection{Medical Screening through Medical History and Physical Examination}

At the beginning and at the end of this study, demographic information, CV risk factors, comorbid conditions, Rutherford class of ischemia, ankle-brachial index (ABI), ankle pressure (AK) and photoplethysmography (PPG), blood and muscle samples and a list of current medications were collected from the medical history of each patient.

\subsection{Inclusion/Exclusion/Withdrawal Criteria}

\subsubsection{Inclusion Criteria:}

- Age of 18 year or older.

- Diagnosis of CLTI: presence of trophic lesions and/or rest pain plus ABI less than 0.4 and/or AP $<50 \mathrm{mmHg}$ or plain or damped PPG curves or toe pressure (TP) $<30 \mathrm{mmHg}$ [30].

- Failure of a previous attempt of revascularization; patients considered at high risk of failure or at high risk of surgical complications during the procedure or in poor conditions for surgery.

- High risk of limb loss.

2.3.2. Exclusion Criteria:

- Pregnancy

- Legally incapacitated.

- Current cancer or during the last 5 years before the study.

- Current pneumonia or sepsis or severe foot infection.

- Untreated hypothyroidism and/or hypocortisolism.

2.3.3. Withdrawal Criteria:

- Patient's own request.

- Decision of the physician due to adverse reactions supposedly secondary to the drug.

- Pneumonia/sepsis during the period of treatment.

- Increase in levels of IGF-I more than 2 standard deviations.

- Increase in tumor markers.

37 consecutive subjects met the inclusion criteria. There were 2 deaths after signing the informed consent and before starting any treatment. Therefore, 35 patients were finally eligible for the study. However, both baseline and final muscle samples were obtained in 29 patients (GH: 16; placebo: 13) who completed the trial without amputation in the referred treatment period ( 2 months).

\subsection{Measurements}

2.4.1. $A B I$ and $A P$ : The method used for determination of $\mathrm{ABI}$ and $\mathrm{AP}$ has been extensively described and recently reviewed [31,32]. A bidirectional continuous doppler with an $8 \mathrm{MHz}$ probe and specific software (Hadeco, es-100V3 model, Quermed S.A) was used for curve analysis.

2.4.2. Inflammatory and vascular circulating biomarkers: A blood sample from a peripheral vein of the forearm was obtained and sent immediately to the central laboratory for determination of plasma biomarkers. The markers and their reference values were: tumor necrosis factor-alpha (TNF- $\alpha$ ): $<8.1 \mathrm{pg} / \mathrm{ml}$; high-sensitivity C-reactive protein (hs-CRP): $<$ $0.5 \mathrm{mg} / \mathrm{dl}$ or $5 \mathrm{mg} / \mathrm{L}$; beta- 2 microglobulin $(\mathrm{B}-2 \mathrm{M}):<0.25 \mathrm{mg} / \mathrm{L}$; cystatin $\mathrm{C}(\mathrm{CyC}): 0.53-0.95$ mg/L; Fibrinogen: 200-430 mg/dl; Glycosylated hemoglobin (HbA1C): <5.5\%; Insulin-like growth factor I (IGF-I) and IGF-I binding protein 3 (IGF-I-BP3): age-standardized values according to our laboratory reference values. Quantifications were performed by using ELISA technique according to the manufacturer's protocols. TNF- $\alpha$, IGF-I and IGF-BP3 were measured using IMMULITE 2000 IMMUNOASSAY SYSTEM (Siemens); for B-2M 
and CyC the DIMENSION VISTA 1500 (Siemens) was used; for hs-CRP, ADVIA 2400 CHEMISTRY SYSTEM (Siemens); for HbA1C, HPLC ADAMS A1C HA-8180 (Arkray); cells count was performed using ADVIA 2120 HEMATOLOGY SYSTEM (Siemens); and Fibrinogen was measured using ACL TOP 550 (Werfen).

The reference value of NLR in general population is considered 2.15. In PAD patients it ranges between 2.5 and 5.25 in different studies. A cut-off point for elevated NLR has not been properly defined for PAD, though the recommendation is to consider a value between 2.5 and 3 [25]. In our study, a value $\geq 2.5$ was chosen as elevated.

2.4.3. Skeletal muscle samples: Samples were taken from the soleus muscle using a cutting trocar and local anesthesia with $2 \%$ lidocaine. In the internal aspect of the leg a small skin incision of 2-3 mm was made. Then, the trocar was inserted until the desired level and a muscle cylinder was removed. Once extracted, the samples were conserved in RNA-later (Invitrogen) at $4^{\circ} \mathrm{C}$, and finally stored at $-80^{\circ} \mathrm{C}$ until analysis.

2.4.4. Real-time PCR (RT-qPCR): Once the RNA was extracted from all the samples, concentration was measured in a Nanodrop spectrophotometer.

RNA extraction was performed using TRIzol ${ }^{\mathrm{TM}}$ reagent (15596026, Invitrogen), following manufacturer instructions. A commercial human skeletal muscle. Total RNA pool (636534, Clontech, USA) was used as reference.

1 microgram of total RNA was incubated with 1 IU RNase free DNase I (EN0521, Thermo), $5 \mu \mathrm{L} 10 \mathrm{X}$ buffer with $\mathrm{MgCl} 2$ and water for a total volume of $50 \mu \mathrm{L}$, at $37^{\circ} \mathrm{C}$ for 30 min. The reaction was terminated by inactivating DNase and then RNA was purified with an affinity column using the GeneJET RNA Cleanup and Concentration micro kit (K0842, Thermo Fisher). RNA was finally quantified by spectrophotometry (Nanodrop 2000, Thermo Fisher). Previous to cDNA synthesis, we performed a second with DNase incubating $1 \mu \mathrm{g}$ of RNA with 1 IU of RNase-free DNase I (EN0521, Thermo Fisher), $1 \mu \mathrm{L}$ of $\mathrm{MgCl} 2$ buffer and water to a final volume of $10 \mu \mathrm{L}$ for $30 \mathrm{~min}$ at $37^{\circ} \mathrm{C}$. DNAse was then inactivated by adding $1 \mu \mathrm{L}$ of EDTA and incubating for $10 \mathrm{~min}$ at $65^{\circ} \mathrm{C}$. cDNA was synthesized following the supplier's protocol, adding 1.5 $\mu \mathrm{L}$ of $300 \mathrm{IU}$ MMLV (28025-013, Invitrogen, USA), $6 \mu \mathrm{L}$ 5X First-Strand Buffer, $1.5 \mu \mathrm{L} 10 \mathrm{mM}$ dNTPs, $0.1 \mu \mathrm{L}$ Random Primers, $3 \mu \mathrm{L}$ 0.1 M DTT, $1 \mu \mathrm{L}$ RNaseOUT ${ }^{\mathrm{TM}}$ Recombinant Ribonuclease Inhibitor (40 units $/ \mu \mathrm{L}$ ) and $\mathrm{H} 2 \mathrm{O}$ for a total $30 \mu \mathrm{L}$ reaction. For human samples, 50, 25, and $12.5 \mathrm{ng}$ of Poly A+ mRNA was similarly treated.

Expression was detected by qPCR using $1 \mu \mathrm{L}$ of the cDNA reaction plus $6 \mu \mathrm{L} 2 \mathrm{x}$ TaqMan Gene Expression MasterMix (4369016 Applied Biosystems) and $6 \mu \mathrm{L}$ diluted primers in 96 well-plates in a 7500 Real-Time PCR System (4351105, Applied Biosystems, USA). As control for general gene expression we used human negative controls of the reverse-transcription step (all reagents and RNA sample but without reverse transcriptase) and the PCR step (all reagents but no reverse-transcribed sample) were included in each assay plate. We used the house keeping gene (TBP) as an expression control gene since we have previous experience in human tissue samples [33,34].

$\Delta \mathrm{Ct}$ relative values respect to the commercial pool of human muscle were calculated for each gene related to TBP. When compared from time zero (control time) to two months of treatment/placebo, $\Delta \Delta \mathrm{Ct}$ values were obtained. Primer sets and TaqMan assays (Applied Biosystems) used are shown in Figure 1. 


\begin{tabular}{|c|c|c|c|}
\hline Gene & Sequence & Amplification size & Annealing $\mathrm{T}^{\mathrm{a}}$ \\
\hline \multirow{3}{*}{ TBP } & Fw: 5'- GCCCGAAACGCCGAATAT -3' & \multirow{3}{*}{$67 \mathrm{bp}$} & \multirow{3}{*}{$60^{\circ} \mathrm{C}$} \\
\hline & Rv: 5' - TTCGTGGCTCTCTTATCCTCATG -3' & & \\
\hline & $\mathrm{Pb}: 5^{\prime}$ - TCCCAAGCGGTTTGCTGCGGTA -3' & & \\
\hline VEGFA & Applied Biosystems: Hs00900055_m1 & $67 \mathrm{bp}$ & $60^{\circ} \mathrm{C}$ \\
\hline IGF-I & Applied Biosystems: Hs01547656_m1 & $68 \mathrm{bp}$ & $60^{\circ} \mathrm{C}$ \\
\hline NOS3 & Applied Biosystems: Hs01574665_m1 & $86 \mathrm{bp}$ & $60^{\circ} \mathrm{C}$ \\
\hline MSTN & Applied Biosystems: Hs00976237_m1 & $69 \mathrm{bp}$ & $60^{\circ} \mathrm{C}$ \\
\hline Nox4 & Applied Biosystems: Hs01379108_m1 & $64 b p$ & $60^{\circ} \mathrm{C}$ \\
\hline MYOG & Applied Biosystems: Hs01072232_m1 & $76 \mathrm{bp}$ & $60^{\circ} \mathrm{C}$ \\
\hline$K D R$ & Applied Biosystems: Hs00911700_m1 & $83 \mathrm{bp}$ & $60^{\circ} \mathrm{C}$ \\
\hline$\pi l-6$ & Applied Biosystems: Hs00174131_m1 & $95 \mathrm{bp}$ & $60^{\circ} \mathrm{C}$ \\
\hline TNF- $\alpha$ & Applied Biosystems: Hs00174128_m1 & $80 \mathrm{bp}$ & $60^{\circ} \mathrm{C}$ \\
\hline
\end{tabular}

Figure 1. Real-time PCR (RT-qPCR). Primer sets and TaqMan assays used in the GHAS trial for muscle gene expression analysis.

\subsection{Statistical Analysis}

Mean, median, standard deviation and standard error values were calculated for each group. Serum biomarkers and molecular data were analyzed at baseline, and for differences between basal and final time-points in the two groups of CLTI patients under GH or placebo. Results were also stratified by patients with or without DM.

The initial step was to check if data within a group followed a normal distribution and if their variances were equal or not. For normality distribution it was used the ShapiroWilk test (as the sample size was less than 50) and Fisher's test for variances. Based on the results, if the groups were normal and homoscedastic we used t-test; if the groups were normal and not homoscedastic we used t-test with Welch's correction; finally, if the groups followed a non-normal distribution we used the test of Wilcoxon-Mann Whitney. To compare among qualitative, or quantitative to qualitative variables, $\mathrm{X}^{2}$ test was performed.

Correlations ( $\mathrm{r}$ ) were measured using the program SPSS ${ }^{\circledR}$, mainly the Spearman correlation coefficient for non-normal qualitative or quantitative variables. All the graphs were constructed by using the program Graphpad prism ${ }^{\circledR}$ program. R statistics with Kaplan-Meier curves and AUC was chosen for NLR measurements and graphs. Fisher and Mantel-Haenszel tests were used for odds ratios analysis.

In addition to the univariate study, a multivariate study was addressed by using multiple logistic regression analysis.

\section{Results}

\subsection{General Characteristics}

The baseline characteristics between both arms of the study were similar in terms of age, sex, hypertension (HT), DM with or without neuropathy, chronic kidney disease (CKD), dialysis, heart disease or Rutherford class. However, on the one hand, some differences were detected between groups on tobacco consumption, with a higher number of non-smokers in the intervention group (GH: $88.89 \%$ vs placebo: $50 \%, p=0.0107)$. On the other one hand, the presence of trophic lesions in the foot was more frequent in the $\mathrm{GH}$ group, favoring the placebo group (GH: $83.3 \%$ vs placebo: $50 \%, \mathrm{p}=0.0381$ ). In CLTI studies, a higher proportion of men is usually found as was in our study (M:W 79.4\% vs $20.6 \%$ ), since this disease has a higher incidence in men. Nevertheless, this fact affected both groups equally: $\mathrm{GH}(72.2 \%$ vs $27.78 \%)$ and placebo $(87.5 \%$ vs $12.5 \%)$, $\mathrm{p}=0.2715$. Our group has previously published a table with all these characteristics (see Table 2 in [27]).

\subsection{Hemodynamic parameters and Plasma biomarkers}

The baseline characteristics (mean and median) of the hemodynamic and plasma parameters are schematized in Table 1: Age: 71.5 \pm 12.4 ; ankle-brachial index (ABI): $0.23 \pm 0.23$; ankle pressure (AP): $38.6 \pm 37.02$; TNF- $\alpha: 10.66 \pm 4.9 \mathrm{pg} / \mathrm{ml}$; hs-CRP: $1.6 \pm 2.2 \mathrm{mg} / \mathrm{dl}$; СуC: $1.45 \pm 0.9 \mathrm{mg} / \mathrm{L}$; B2M: $0.4 \pm 0.3 \mathrm{mg} / \mathrm{L}$; Fibrinogen: $560.21 \pm 128.51 \mathrm{mg} / \mathrm{dl} ; \mathrm{HbA1C}$ : 
$6.5 \pm 1.02 \%$; Neutrophil-to-lymphocyte ratio (NLR): $3.5 \pm 2.8$; IGF-I: $134.9 \pm 53.2 \mathrm{ng} / \mathrm{ml}$; IGFIBP3: $3.06 \pm 1.1 . \mu \mathrm{g} / \mathrm{ml}$.

Table 1. Mean and median results of inflammatory parameters in CLTI patients from the GHAS trial. TG: Triglycerides; HDLc: High density lipoprotein; LDLc: Low density lipoprotein; ABI: Ankle-brachial index; AP: Ankle pressure; IGF-I: Insulinlike growth factor; IGFBP3: IGF-I binding protein 3; TNF- $\alpha$ : Tumor necrosis factor alpha; hsCRP: C-reactive protein of high sensitivity; B2M: Beta-2 microglobulin; CyC: Cystatin C; HbA1C: Glycosylated Hemoglobin; NLR: Neutrophil-to-lymphocyte ratio; Fibrinog: Fibrinogen; SD: standard deviation; Min: minimum; Max: maximum.

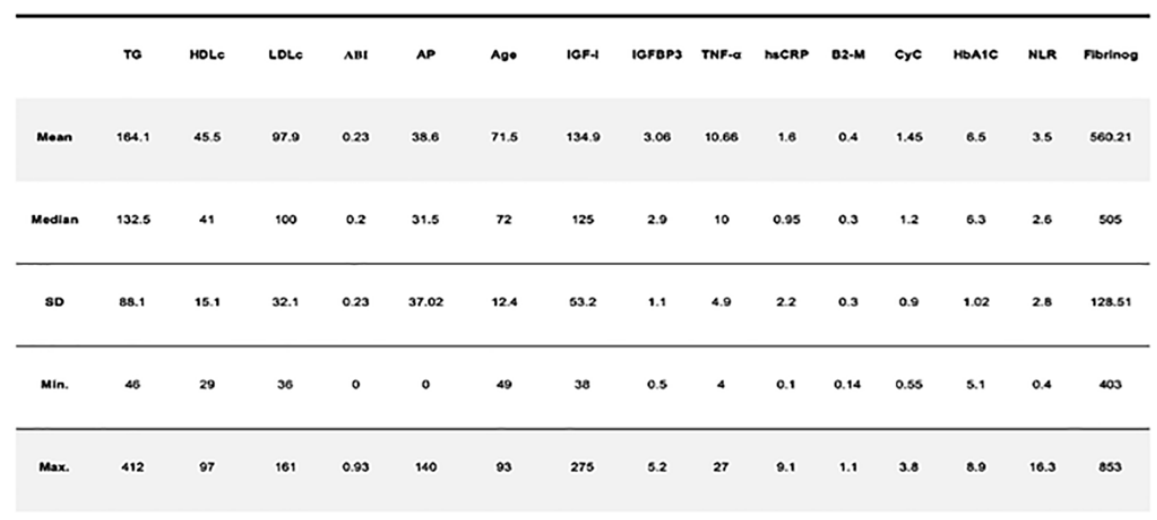

Elevated level of TNF- $\alpha(\geq 8.1 \mathrm{pg} / \mathrm{ml})$ was seen in $68.57 \%$ of patients $(\mathrm{GH}: 83.3 \%$; Placebo: $52.9 \%$ ), while high level of hs-CRP ( $\geq 0.5 \mathrm{mg} / \mathrm{dl}$ ) was detected in $60.5 \%$ (GH: $70 \%$; Placebo: $50 \%$ ). An elevated NLR ( $\geq 2.5$ ) appeared in $52.6 \%$ of patients with CLTI in this trial and $\mathrm{CyC}$ was also increased in the GH group compared with placebo. IGF-I increased in $8.11 \%$ of patients, mainly in the GH group, and IGFBP3 was found low in $44.1 \%$ of patients.

Table 2 depicts relevant information about groups. As can be see, the level of biomarkers of inflammation such as TNF- $\alpha$, hs-CRP and CyC was significantly higher in the GH group at baseline, which implies a higher inflammatory state in this group. Even basal levels of fibrinogen were higher in GH group (601.25 vs 489.85, $\mathrm{p}=0.0425)$, which supports this statement. At the end of the study, only plasma TNF- $\alpha$ was significantly decreased compared to placebo, as previously reported by our group [27].

Table 2. Biomarkers distribution in the GHAS study. Basal: baseline or pretreatment values; Final: final values after 2 months of treatment. Statistical significance is highlighted in colors.

\begin{tabular}{|l|ccc|ccc|c|}
\hline & \multicolumn{3}{|c|}{ GH Group } & \multicolumn{3}{c|}{ Placebo } & \\
\hline Basal TNF- $\alpha$ & 16 & 12.35 & 5.2 & 16 & 8.78 & 3.9 & 0.0184 \\
\hline Final TNF- $\alpha$ & 15 & 10.93 & 5.12 & 14 & 8.04 & 3.6 & 0.0464 \\
\hline Basal hs-CRP & 18 & 2.07 & 2.86 & 16 & 0.79 & 0.70 & 0.0454 \\
\hline Final hs-CRP & 17 & 1.1 & 1.38 & 14 & 3.42 & 7.51 & 0.2188 \\
\hline Basal B2M & 7 & 0.47 & 0.27 & 16 & 0.22 & 0.08 & 0.1269 \\
\hline Final B2M & 8 & 0.56 & 0.51 & 14 & 0.21 & 0.12 & 0.3894 \\
\hline Basal CyC & 7 & 1.75 & 0.93 & 4 & 0.76 & 0.17 & 0.035 \\
\hline Final CyC & 8 & 1.71 & 1.12 & 2 & 0.8 & 0.14 & 0.3054 \\
\hline
\end{tabular}

\subsection{Basal mRNA expression}

After analyzing the basal mRNA expression of different genes in the skeletal ischemic muscle (Figure 2, A-H), it was found that only NOX4 had a consistent higher expression 
in the group of DM and GH compared to the group without DM and placebo ( $p=0.0346)$ (Figure 2, A).

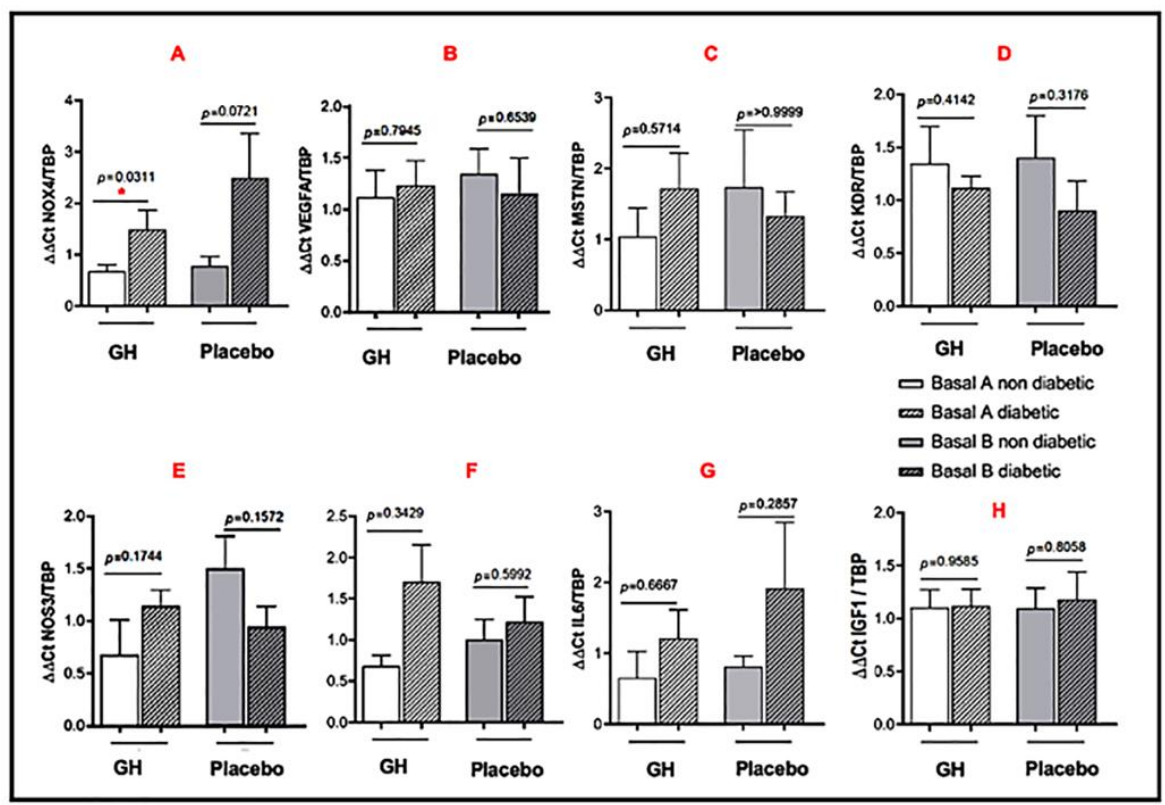

Figure 2. mRNA expression of different genes at baseline in both groups, GH and placebo) in DM and non-DM patients. A. NOX4: NADPH (Nicotinamide Adenine Dinucleotide Phosphate oxidase) 4; B. VEGFA: Vascular Endothelial Growth Factor A; C. MSTN: Myostatin; D. KDR: VEGFA receptor 1. E. NOS3 or eNOS: Nitric Oxide Synthase 3 or endothelial NOS; F. MYOG: Myogenin; G. IL6: Interleukin 6; H. IGF-I: Insulin-Like Growth Factor I. * $\mathrm{p}<0.05$.

\subsection{Basal and Final mRNA expression}

NOX4 mRNA expression underwent a real decrease in DM ischemic patients treated with GH compared to non-DM ( $\mathrm{p}=0.0348$ ) (Figure 3, A). TNF- $\alpha$ mRNA expression was not reduced in the intervention group, neither in patients with DM nor in those without DM (Figure 3, B). The angiogenesis marker KDR underwent a real increase in its expression during GH treatment, which was only significant in patients with DM $(\mathrm{p}=0.036)$ (Figure 3, C).

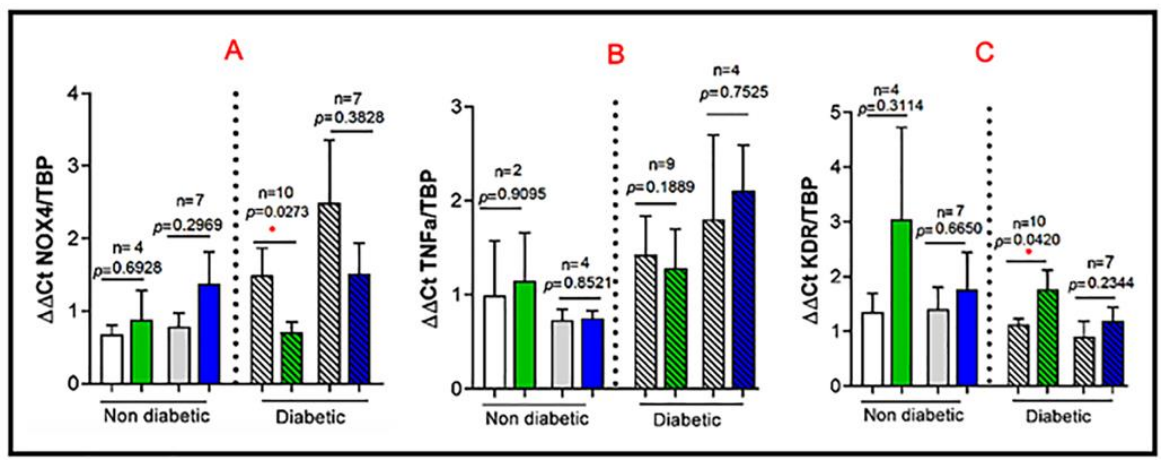

Figure 3. Basal to final mRNA expression of different genes. NOX4 (A), TNF- $\alpha$ (B) and KDR $(\mathbf{C})$. Findings in both groups, GH and placebo, with DM and without DM. ${ }^{*} \mathrm{p}<0.05$.

\subsection{Plasma biomarkers and mRNA expression}

Figure 4 depicts the relationship between basal plasma TNF- $\alpha$ and gene expression in ischemic skeletal muscle for DM patients in both groups of treatment (GH and placebo). First, a positive correlation was found between plasma TNF- $\alpha$ level and mRNA expression of TNF- $\alpha(\mathrm{r}=0.588, \mathrm{p}=0.035)$ (Figure $4, \mathrm{~A})$, that was especially relevant for those patients 
with TNF- $\alpha \geq 8.1(\mathrm{r}=0.802, \mathrm{p}=0.001)$ (see also Table 3). Second, there was an inverse correlation between the expression of TNF- $\alpha$ and NOS3 $(r=-0.4999, p=0.0151)$, more evident for those in the GH group ( $\mathrm{r}=-0.78, \mathrm{p}=0.0064$ ) (Figure 4, B). Third, an inverse correlation was found between TNF- $\alpha$ and the angiogenic factor VEGFA ( $r=-0.4321, p=0.0395)$, also stronger in the GH group ( $\mathrm{r}=-0.7727, \mathrm{p}=0.0074)$ (Figure 4, C). Fourth, the high level of inflammation, expressed by TNF- $\alpha \geq 8.1$, related to the expression of IGF-I ( $\mathrm{p}=0.0010)$, with a moderate but good positive correlation between both $(r=0.5192, p=0.0111)$ (Figure 4 , D). All these relationships, as mentioned above, appeared exclusively or were stronger in patients with DM.

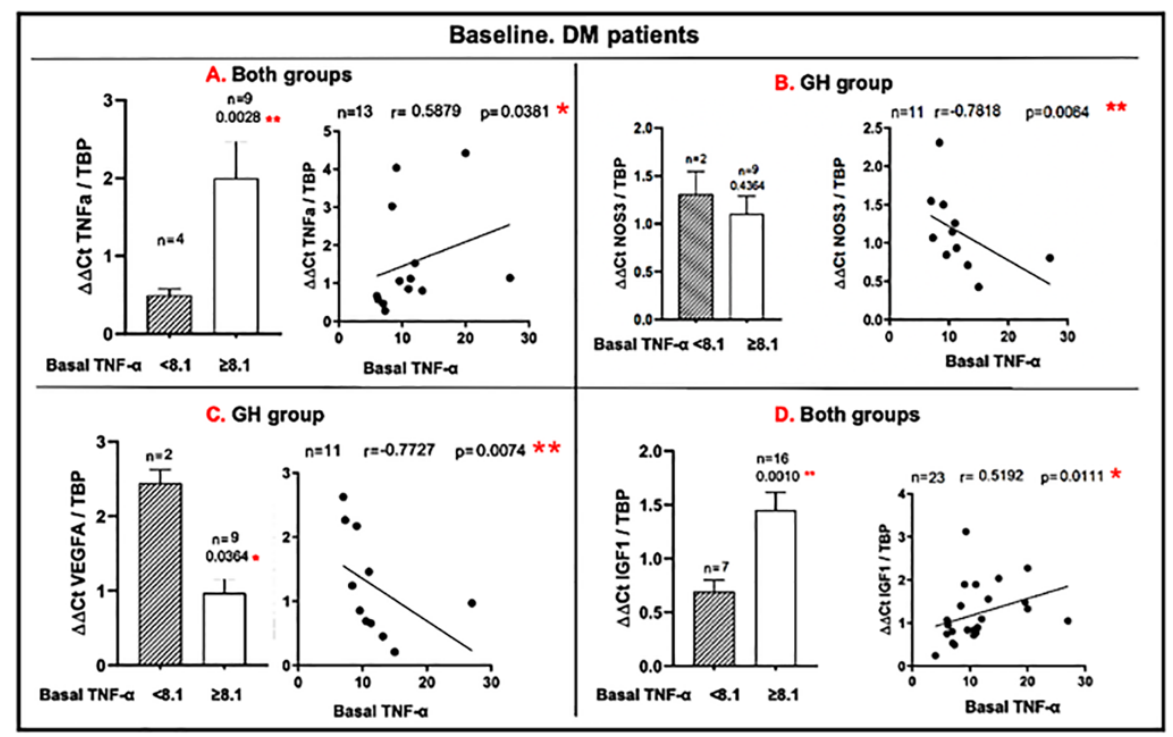

Figure 4. Baseline plasma levels of TNF- $\alpha$ related to different muscle gene expressions in DM patients. Both groups: $\mathrm{GH}$ and placebo. Correlation between plasma TNF- $\alpha$ and muscle TNF- $\alpha$ (A), NOS3 (B), VEGFA (C) and IGF-I (D) mRNA expressions. ${ }^{*} \mathrm{p}<0.05 ;{ }^{* *} \mathrm{p}<0.001$.

In addition, those patients with the highest levels of TNF- $\alpha$ at baseline had higher levels of redox stress $(\mathrm{p}=0.0475)$, with a weak but significant correlation between TNF- $\alpha$ and NOX4 ( $\mathrm{r}=0.35, \mathrm{p}=0.0375$ ) (Figure 5, A). Interestingly, the latter relationship shows different behavior depending on TNF- $\alpha$ values $\geq 8.1$ or $<8.1$ (Figure $5, \mathrm{~B}$ ). It should be noted that patients without DM showed the best correlation between both markers $(0.645, \mathrm{p}=0.032)$, especially when TNF- $\alpha$ reached $\geq 8.1 \mathrm{pg} / \mathrm{ml}(\mathrm{r}=0.717, \mathrm{p}=0.009)$ (see further in the text in Table 3). 


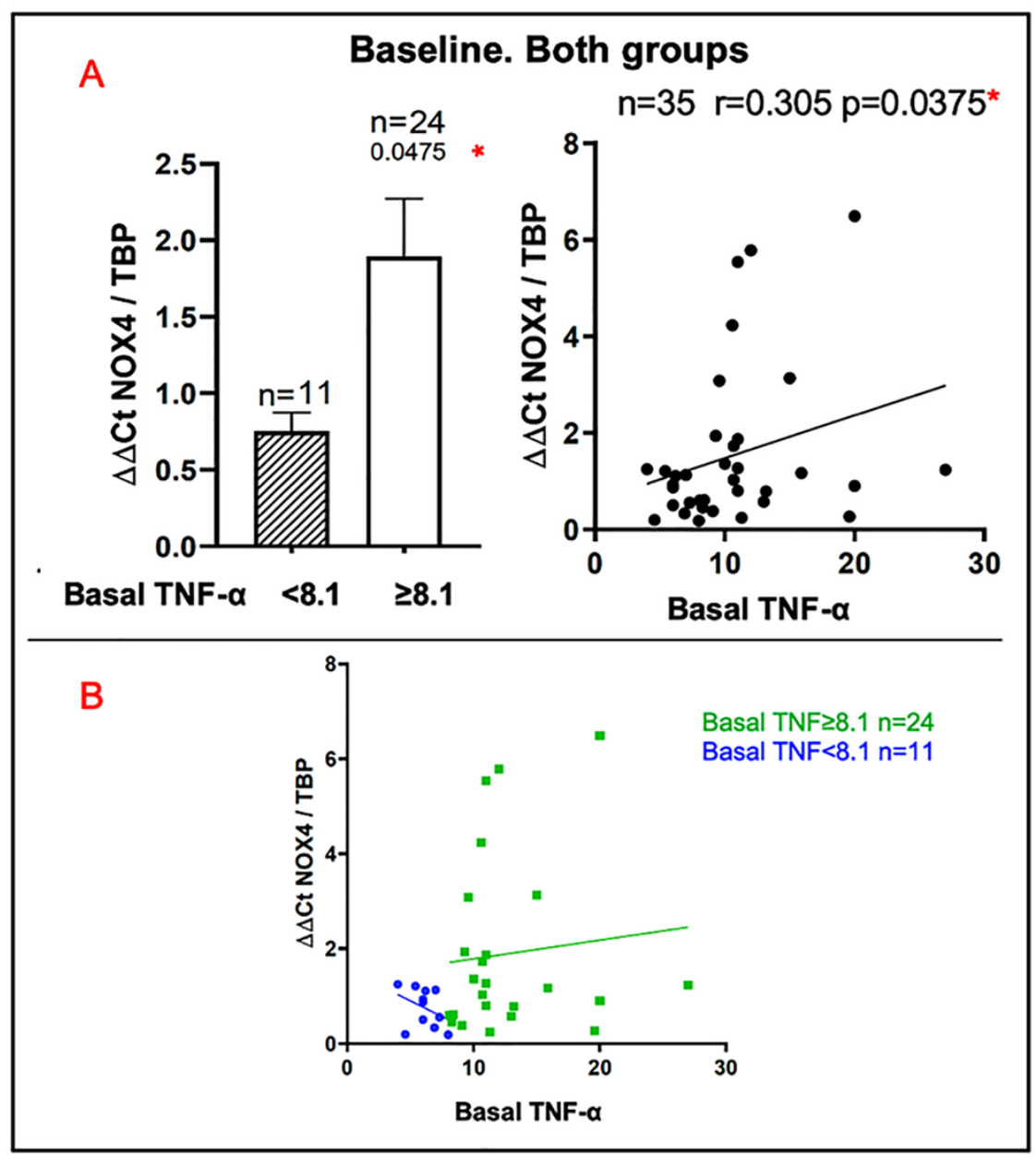

Figure 5. Relationship between high levels of TNF- $\alpha(\geq 8.1 \mathrm{pg} / \mathrm{ml})$ and NOX4 expression. Both groups: GH and placebo. A. Left: expression of muscle NOX4 mRNA in relation to plasma TNF- $\alpha$. Striped bar: TNF- $\alpha<8.1 \mathrm{pg} / \mathrm{ml}$. White bar: TNF- $\alpha \geq 8.1$ $\mathrm{pg} / \mathrm{ml}$. A. Right: Spearman correlation between both markers. B. Trend of this correlation differentiating by TNF- $\alpha$ values: $\geq 8.1$ (green color) and $<8.1$ (blue color). ${ }^{*} \mathrm{p}$ $<0.05$.

High level of hs-CRP at the beginning of the study was related to NOS3 expression at baseline $(r=-0.74, p=0.009)$, also in patients with $D M$, although this fact was only observed in the group treated with GH (Figure 6, A), while at the end of the study (final time-point) a value of hs-CRP $\geq 0.5$ was negatively correlated to muscle NOS3 expression, both in patients with DM and without DM treated with GH ( $\mathrm{r}=-0.711, \mathrm{p}=0.021)$ (see Table 3).

Basal hs-CRP had a negative association to basal VEGFA expression too, in both groups of treatment (GH and placebo), although specifically in DM ( $r=-0.632, p=0.005)$ and for those with the highest levels of inflammation measured by hs-CRP $\geq 0.5$ ( $p=0.0330$ ) (Figure 6 , B). Final hs-CRP was also related to final expression of NOX4, although only in the GH group $(r=0.7, p=0.0041$ ) (Figure 6, C), while the relationship with MSTN expression was negative $(\mathrm{r}=-0.7604, \mathrm{p}=0.009)$ (Figure 6, D). 


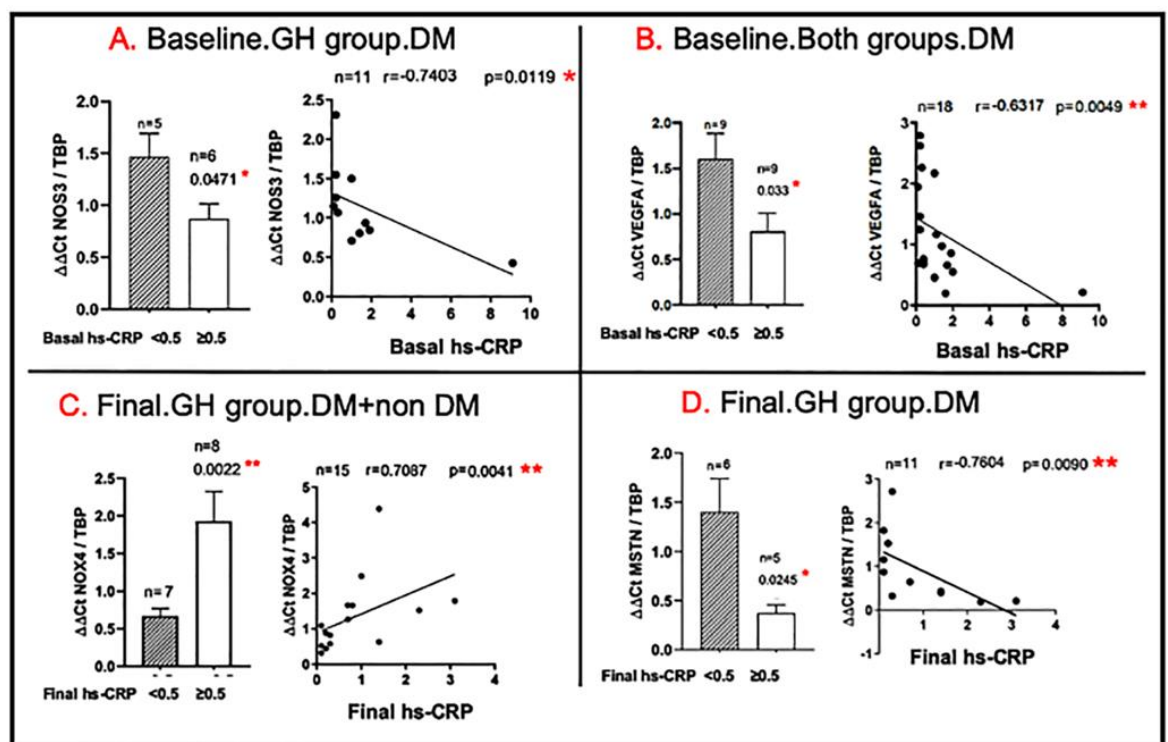

Figure 6. Correlation between hs-CRP and muscle gene expression. A. Baseline expression levels of hs-CRP and NOS3 in the GH group in patients with DM. B. Baseline hs-CRP and VEGFA levels in both groups in patients with DM. C. Final hs-CRP and redox stress levels measured by final NOX4 in the GH group in patients with and without DM. D. Final hs-CRP levels are related to final MST mRNA expression in GH group diabetic patients. Striped bars: hs-CRP $<0.5$; White bars: hs-CRP $\geq 0.5$. * $\mathrm{p}<0.05 ;{ }^{* *} \mathrm{p}<0.001$.

Of interest are also plasma $\mathrm{HbA} 1 \mathrm{C}$ correlations at baseline. Indeed, $\mathrm{HbA1C}$ was highly correlated to TNF- $\alpha$ mRNA expression of in the GH group with DM $(r=0.7280, p=0.0321)$ (Figure 7, A). The same occurred between $\mathrm{HbA1C}$ and IGF-I mRNA expression in patients with DM, but, in this case, in both groups of patients, GH and placebo $(r=0.7, p=0.0039)$ (Figure 7, B). At the end of the treatment, the final level of $\mathrm{HbA1C}$ was also inversely related to final muscle expression of VEGFA in DM, but only in the placebo group $(\mathrm{r}=$ $0.9747, \mathrm{p}=0.0333)$ (Figure 7, C).

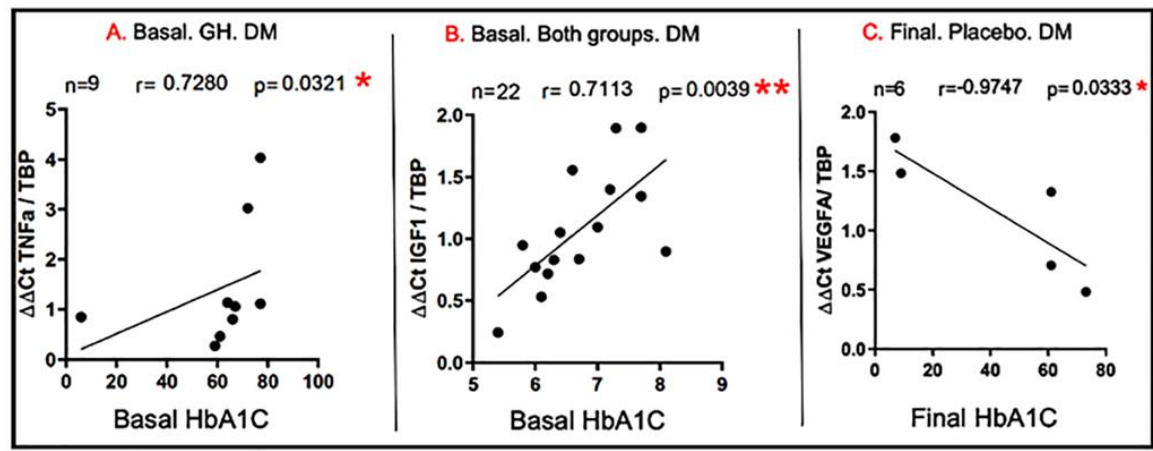

Figure 7. Correlation of plasma HbA1C and muscle mRNA expression. A. TNF- $\alpha$.

B. IGF-I. C. VEGFA. A and B represent correlations at baseline, while $\mathbf{C}$, at final timepoint. ${ }^{*} \mathrm{p}<0.05 ;{ }^{* *} \mathrm{p}<0.001$.

As our group has previously published, NOX4 expression was specifically reduced in the GH-treated group ( $\mathrm{p}=0.025$ ), while it tended to increase in the placebo group (see Figure 5 in [27]).

All correlations between plasma markers and mRNA expression are summarized in Table 3.

Table 3. Summary of correlations between plasma biomarkers and gene expression. ${ }^{*}$ Indicates that this condition was also found significantly associated in nonDM population of the GHAS trial. 


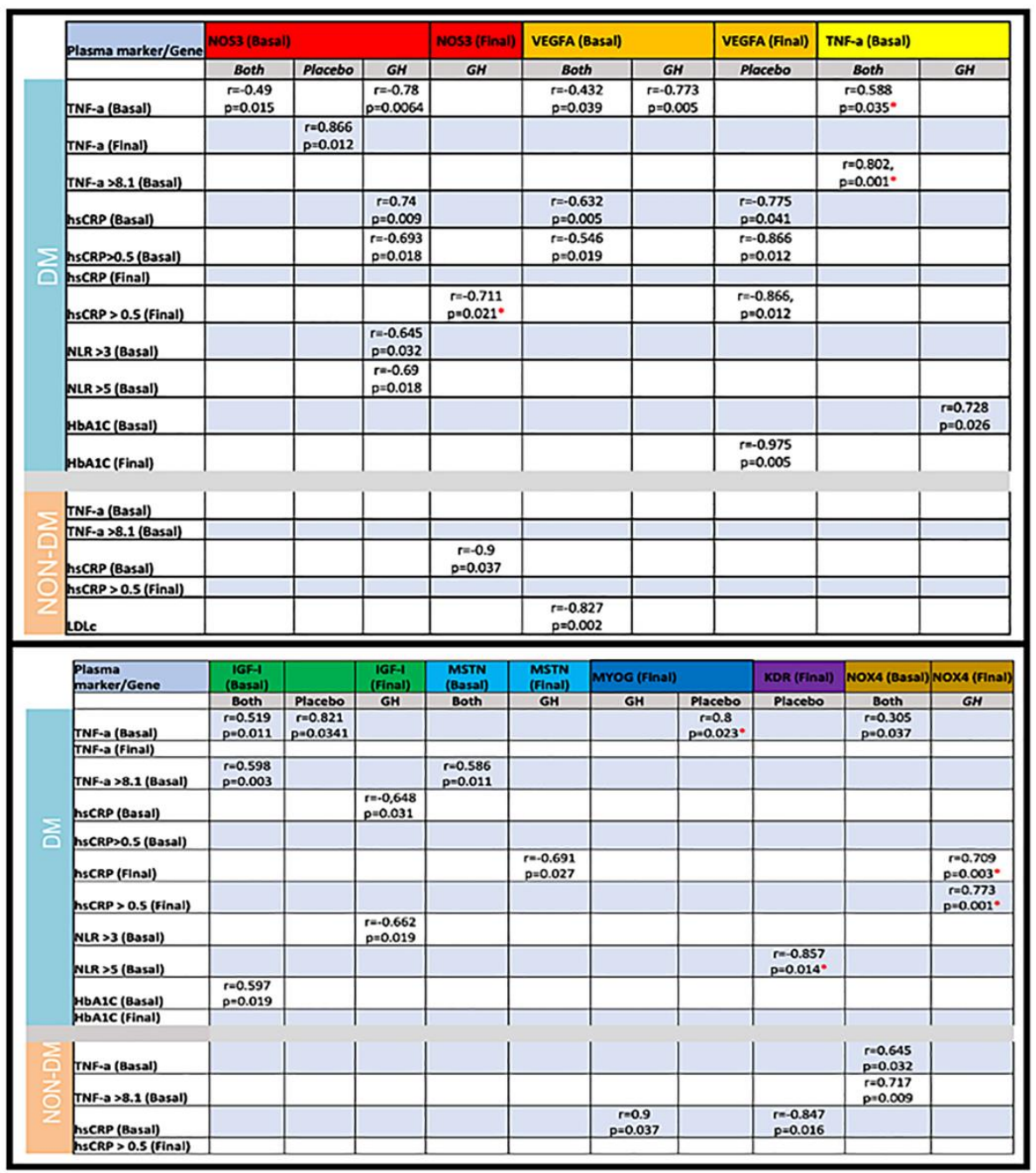

\subsection{Mortality in the GHAS trial}

Special attention to mortality was made in the GHAS trial. The cumulative mortality at 12-months reached $47.4 \%$ of CLTI patients, being higher, although not significant, for GHtreated patients both at 2 months $(5.5 \%$ vs $0 \%, p=0.42)$ and at 12 months $(29.4 \%$ vs $12.5 \%$, $\mathrm{p}=0.23$ ) (Table 4).

Table 4. Mortality in the GHAS trial. Short-term mortality: 0-2 months (period of treatment). Long-term mortality: 2-12 months (observation period).

\begin{tabular}{ccccccc}
\multicolumn{8}{c}{ Mortality. GHAS Trial } \\
\hline & 0.2 months & Mortality & p-value & $2-12$ months & Mortality & p-value \\
\hline Placobo & $0 / 16$ & $0 \%$ & & $2 / 16$ & $12.5 \%$ & \\
\hline GH & $1 / 18$ & $5.5 \%$ & 0.42 & $5 / 17$ & $29.4 \%$ & 0.23 \\
\hline Cumulativo & & $5.5 \%$ & & & $47.4 \%$ & \\
\hline
\end{tabular}

It was performed a careful analysis of variables associated to mortality in the GHAS trial, in order to identify some possible predictors. A value of TNF- $\alpha \geq 8.1$ was significantly associated with cumulative mortality at 12-month or long-term mortality $(\mathrm{p}=0.0487, \mathrm{OR}=$ CI (95\%): 0.23-136.6, Fisher test: $\mathrm{p}=0.63$ ) (Figure 8, A), while a value of NLR $\geq 3$ was also significantly associated with ong-term mortality in CLTI patients ( $\mathrm{p}=0.019, \mathrm{OR}=6.9, \mathrm{CI}$ (95\%): 0.71-353.7, $\mathrm{X}^{2}$ with McNemar correction: $\mathrm{p}=0.01946$, Fisher test: $\mathrm{p}=0.093$ ) (Figure 8, B). For NLR $\geq 3$, the Mantel-Haenszel test was also performed, which showed no influence of other variables such as smoking, DM, hs-CRP and TNF- $\alpha$ on the results. $\mathrm{X}^{2}$ 


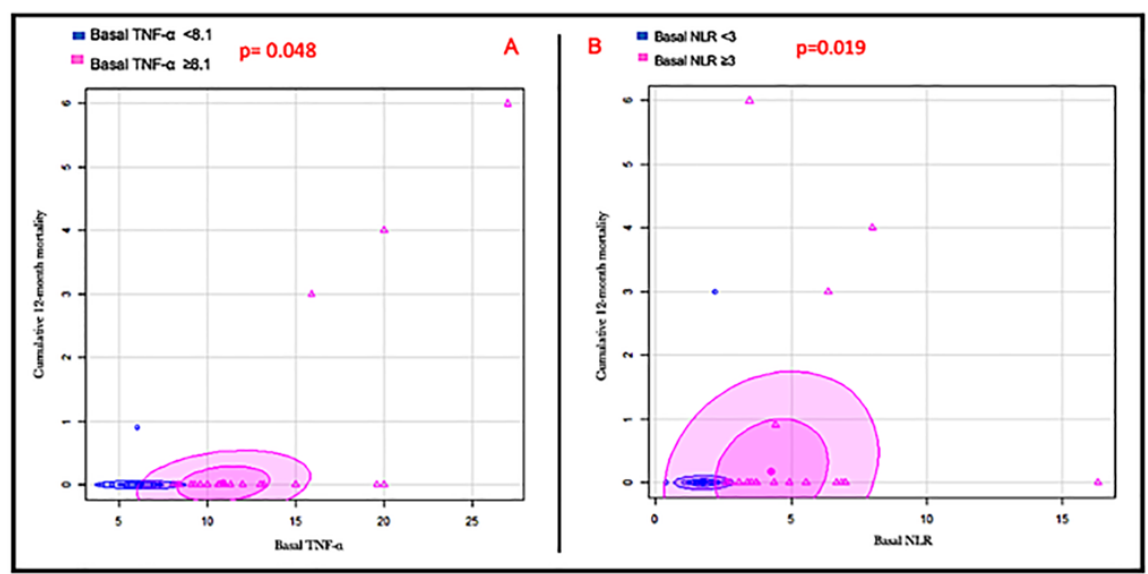

Figure 8. Cumulative 12-month mortality and plasma markers. A. Basal TNF- $\alpha$; B. Basal NLR.

Kaplan-Meier survival analysis showed how patients with NLR $\geq 3$ and $\geq 5$ had a higher mortality rate (Figure 9, A). On the one hand, when we performed AUC curves, we found that the best cut-off point for NLR to predict mortality in CLTI was $3.4(74.2 \%, 85.7 \%)$ with an AUC value of $0.811(0.733-0.857)$, and a power of 0.77 (Figure 9, B). On the other hand, the best cut-off point for TNF- $\alpha$ was $15.4(96.6 \%, 66.7 \%)$, with an AUC value of $0.7989(52.4 \%-100 \%)$ and a power of 0.67 (Figure 9, C). After comparing both biomarkers in terms of their predictive ability, we observed that there were no statistical differences $(p=$ 0.9264) (Figure 9, D).

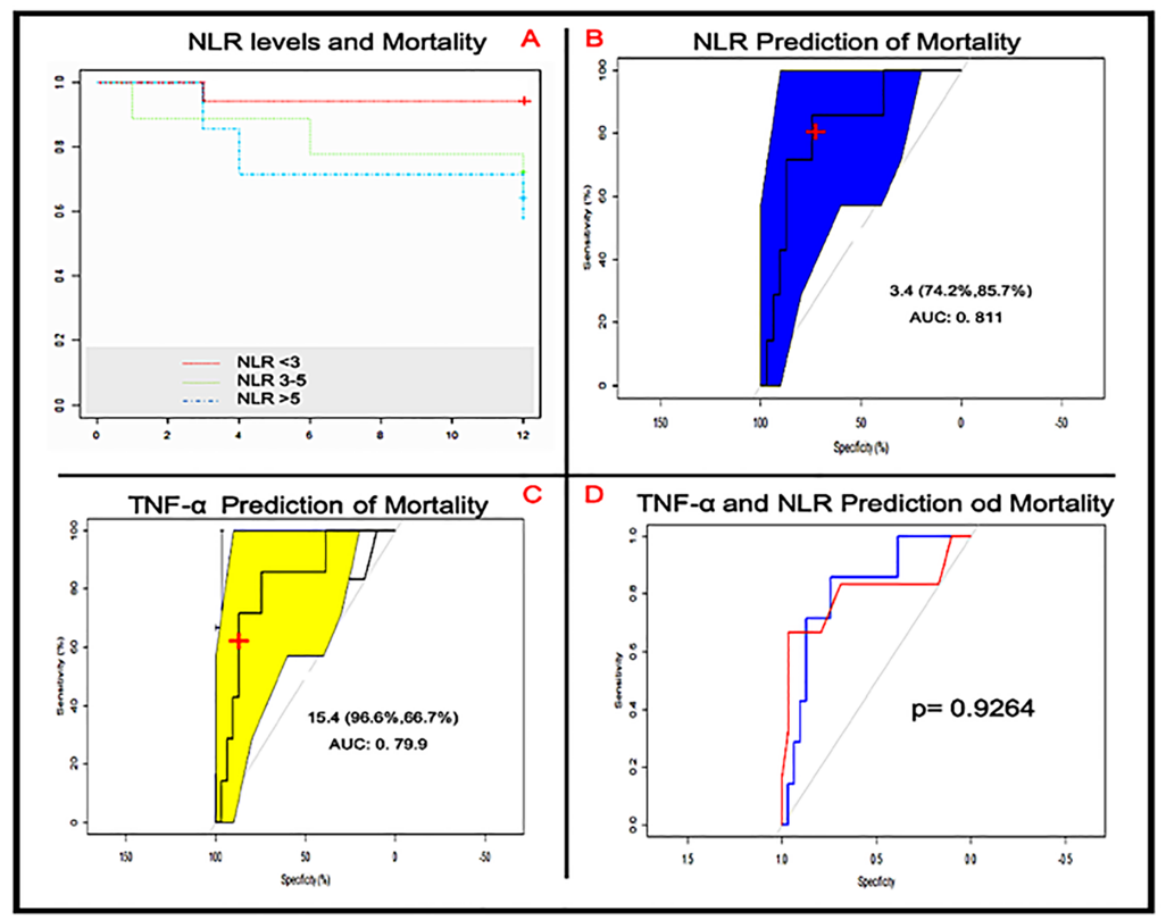

Figure 9. Relationship between NLR and TNF- $\alpha$ with mortality. A. Kaplan-Meier analysis of NLR and mortality. B. AUC curve of NLR related to mortality. C. AUC curve of TNF- $\alpha$ related to mortality. Color blue and yellow represent confidence intervals. D. Comparation between TNF- $\alpha$ and NLR as predictors of mortality.

In addition, some clinical predictors of long-term mortality were also found, such as Chronic Obstructive Pulmonary Disease (COPD) ( $\mathrm{p}=0.042$, OR = 5.8, CI (95\%): 0.84-40.7) and the American Society of Anesthesiologists (ASA) class in which patients with ASA 4 presented elevated levels of deaths compared to ASA3 ( $p=0.0119, \mathrm{OR}=15.75, \mathrm{CI}(95 \%)$ : 0.87-284.9) (Table 5). 
Table 5. Plasma and clinical predictors of mortality in the GHAS trial. COPD: Chronic Obstructive Pulmonary Disease; ASA: The American Society of Anesthesiologists (ASA) class is a system for assessing the risk of patients before surgery. ASA 4 includes patients in extremely poor physical condition for surgery. CI: Confidence Interval.

\begin{tabular}{|r|c|c|c|}
\hline \multicolumn{3}{|c|}{ Predictors of Mortality in the GHAS trial } \\
\hline & p-value & OR & CI (95\%) \\
\hline Basal NLR $\geq 3$ & 0.019 & 6.9 & $0.71-353.7$ \\
\hline Basal TNF- $\alpha \geq 8.1$ & 0.0487 & 2.5 & $0.23-136.6$ \\
\hline COPD & 0.042 & 5.8 & $0.84-40.7$ \\
\hline ASA4-ASA3 & 0.0119 & 15.7 & $0.87-284.9$ \\
\hline
\end{tabular}

It is also noteworthy that the basal level of hs-CRP was related to mortality, but in this case at 2 month or short-term mortality ( $p=0.008$, OR). In addition, the level of NLR at baseline was closely related to the level of hs-CRP $(r=0.5335, p=0.0006)$ (Figure 10, A), specially for the values of hs-CRP $\geq 0.5$ and NLR $>2.5$ ( $\mathrm{p}=0.013$ ) (Figure 10, B).

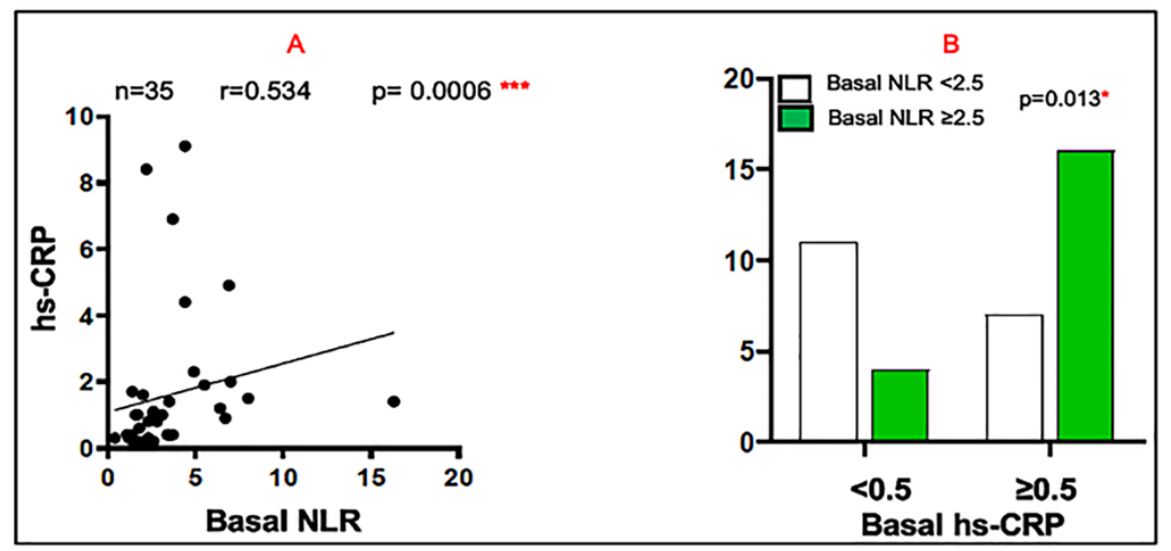

Figure 10. Relationship between basal levels of NLR and hs-CRP. A. Spearman correlation. B. Histogram comparing hs-CRP $\geq 0.5$ and NLR $\geq 2.5$. Green bars: NLR $\geq 2.5$; White bars: NLR $<2.5$. ${ }^{*} \mathrm{p}<0.05$; ${ }^{* *} \mathrm{p}<0.0001$.

\subsection{Statistical study: Measures of association of variables.}

\subsubsection{Univariate analysis}

The linear regression model showed how values of hs-CRP $\geq 0.5 \mathrm{mg} / \mathrm{dl}$ or $5 \mathrm{mg} / \mathrm{L}$ at baseline tended to be related to the cumulative amputation ratio at 12 months $(p=0.056)$. This issue was studied in depth using COR curves, finding that the best cutoff point was $0.7 \mathrm{mg} / \mathrm{dl}$ or $7 \mathrm{mg} / \mathrm{L}$ (AUC: $66.4 \%, 49.3-83.5 \%$ ). However, the statistical power of this association was low (0.2579), supporting the fact that a larger sample size is needed to confirm this possible relation. In the placebo group, final levels of NOX4 were significantly related to the Rutherford class of patients $(\mathrm{r}=0.67, \mathrm{p}=0.011)$, while final IGFI was related to ABI $(r=-0.63, p=0.011)$. In the GH group, the final level of KDR was affected by age $(r=-0.56, p=0.016)$, while the expression of NOS3 correlated positively to 
wound healing $(\mathrm{r}=0.55, \mathrm{p}=0.031)$. At baseline, VEGF-A expression was related to $\mathrm{CKD}(\mathrm{r}=$ $-0.41, p=0.013$ ) (Figure 11, top). The specific relationship between NOX4 expression and Rutherford class has been represented in Figure 11, bottom.

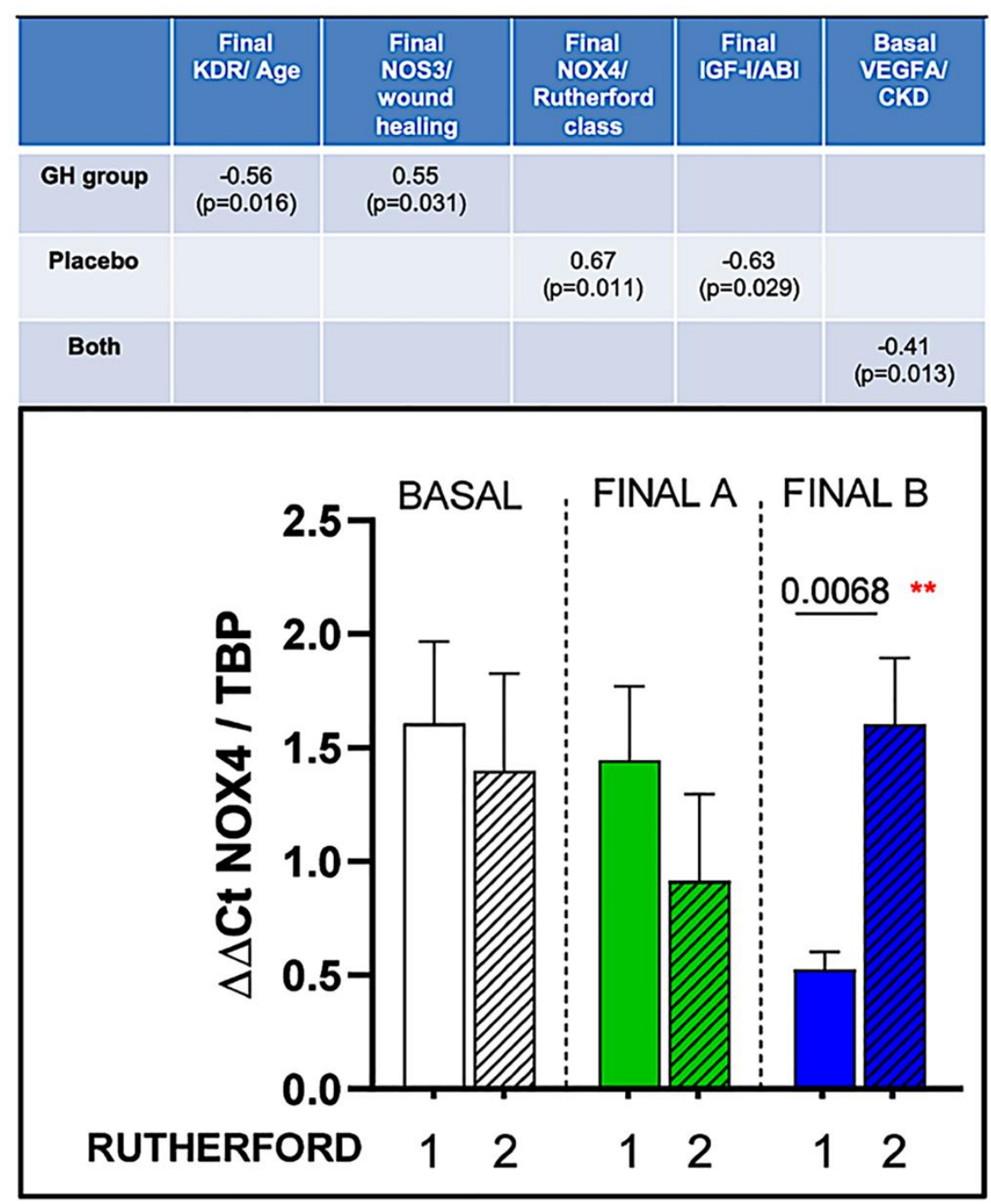

Figure 11. Top: Table showing relations between different muscle genes and clinical variables in both groups. Bottom: graph showing the link between NOX4 mRNA expression and Rutherford class, grouped into two groups: (1: less severity of ischemia; 2: more severity of ischemia). A: GH group; B: Placebo group. White box: basal level of NOX4; Green bars: final level of NOX4 in the GH group; Blue bars: final level of NOX4 in the placebo group. Striped bars: indicate severe ischemia. ** $\mathrm{p}<0.001$.

\subsubsection{Multivariate analysis}

When we used the multiple logistic regression model the relationship between basal NLR $\geq 2.5$ and hs-CRP $\geq 0.5$ was also found ( $p=0.013$ ), which was confirmed by using Kendall's Tau (0.41, p=0.010).

However, high levels of plasma TNF- $\alpha(\geq 8.1)$ at baseline was not related to anything using the multivariate analysis, although there was a trend to be related to basal hs-CRP $\geq 0.5(p=0.055), N L R(p=0.063)$ and CKD ( $p=0.059)$. Basal hs-CRP $\geq 0.5$ was also not related to anything with this model, although with a tendency to be associated with the Rutherford class ( $\mathrm{p}=0.055)$.

\section{Discussion}

In this study we have analyzed the role of some plasma biomarkers and muscle gene expression in the ischemic muscle of PAD patients, focusing on data from the GHAS trial carried out in the special group of patients suffering from CLTI, which shows a high level 
of inflammation and, in parallel, a high morbidity and mortality rate [31]. Most studies have investigated plasma samples from patients with intermittent claudication, a less severe form of PAD, without information on the status of the ischemic muscle. Therefore, the true role of inflammatory cytokines in advanced PAD needs to be better defined. In the GHAS trial, in addition of the study of some prominent plasma markers of inflammation, such as TNF- $\alpha$, hs-CRP or NLR, among others, we cross-linked these data with those obtained from gene expression at the level of ischemic skeletal muscle of the lower extremities.

Our data confirm the high level of inflammation in CLTI patients (see Table 1) and the high mortality rate (see Table 4). Interestingly, patients randomized to the GH group were significantly more affected by inflammation than those in the placebo group, based on data from plasma biomarkers (see Table 2: TNF- $\alpha$, hs-CRP and CyC), offering a special group of very high inflammation within this study that can explain some of the findings of this trial. This is also consistent with the fact that patients in the GH group had significant higher levels of fibrinogen and, as published by our group [27], more trophic lesions in the foot than those in the placebo group, indicating a more severe stage of ischemia. Note, for example, the lipid profile of this series, with a mean LDLc of $97.9 \pm 32.1$ $\mathrm{mg} / \mathrm{dl}$ despite taking statins, which represents a lack of adequate control of this parameter according to current criteria in PAD [35], which favors inflammation. Nevertheless, at the end of the study, only TNF- $\alpha$ experienced a significant reduction in GH-treated patients [27], which is consistent with previous studies [36,37]. This supports both the antiinflammatory action of GH in this setting and the key role of TNF- $\alpha$ in PAD. The effect of GH on hs-CRP did not reach a significant reduction, probably as a consequence of the relatively small sample size of this study. However, the MESA trial or Mendelian randomization studies for hs-CRP have shown neutral results of hs-CRP in PAD [38], considering CRP an acute phase reactant rather than a causal factor [20]. As we have seen in the results of our study, this statement might not be completely true for CLTI patients, as we have found how hs-CRP is related to both angiogenesis (NOS3, VEGFA) and redox balance (NOX4) (Figure 6, A, B, C).

As in our previous study [27], in the present work it is once again demonstrated that oxidative stress plays a crucial role in CLTI. NOX4 was the only gene that our group found elevated in patients with high levels of inflammation and DM (Figure 2, A), which supports the link between these two aspects and the finding that GH reduced this expression.

Although NOX4 was significantly reduced in the entire GH group, the data from the present study show that patients with DM experienced a real decrease in the levels of this enzyme compared to non-DM ( $p=0.0348$ ), establishing that these types of patients could be the most benefited from treatment with the hormone (Figure 3, A).

Plasma TNF- $\alpha$ was significantly reduced in those patients treated with GH. However, a significant reduction in mRNA expression of the same marker was not detected at the level of the ischemic muscle, neither in patients with DM nor in patients without DM (Figure 3, B). This finding is not consistent with the reported fact that plasma TNF- $\alpha$ is positively correlated with TNF- $\alpha$ mRNA. The possible explanation could be related to the hypothesis that GH reduces the cleavage of TNF- $\alpha$ joined to the cell membrane, which is the source of soluble TNF- $\alpha$, lowering the presence of the latter in plasma, but the hormone would not decrease the expression of TNF- $\alpha$ expressed at the cell membrane [39]. It should be emphasized that the binding of TNF- $\alpha$ to the cell membrane depends on cell-cell interaction and, furthermore, there are many polymorphisms of the TNF- $\alpha$ gene, both functional and structural, that affect gene function, mRNA production and its final expression [39]. The complex regulation of the TNF- $\alpha$ gene and the lack of information of the behavior of this gene in clinical studies with ischemia, might explain this finding.

Also of great relevance is the negative correlation between plasma levels of TNF- $\alpha$ and hs-CRP with mRNA expression of the angiogenic markers NOS3 and VEGFA, indicative of the deleterious effect of these cytokines on tissue regeneration related to angiogenesis (Figures 4 and 6). On the one hand, the role of TNF- $\alpha$ in this setting was expected, as it was advanced in a previous experimental study [40]. Nevertheless, our group first confirms that this important fact also occurs in humans with CLTI. Surprising 
was the finding of CRP possibly affecting angiogenesis. The data obtained in this regard confirm that this protein could be associated to homeostasis and angiogenesis in the state of high level of inflammation, as indicated by an experimental study [41]. The latter statement could lead to consider that this protein would have an active role rather than being a passive acute phase reactant. Both biomarkers, TNF- $\alpha$ and hs-CRP, were also negatively correlated to VEGFA expression, supporting their impact on angiogenesis. Other authors have found a relationship between plasma levels of VEGF and hs-CRP in experimental models of stroke [42]. Again, our group is the first to describe the connection between skeletal muscle VEGFA mRNA and plasma hs-CRP in patients with lower limb ischemia.

The mentioned findings are parallel and consistent with the positive significant correlation between basal plasma TNF- $\alpha$ or final plasma hs-CRP and NOX4 in both groups of patients. The data obtained show that TNF- $\alpha$ has a different behavior pattern depending on its levels related to NOX4 expression (Figure 5, B), which supports the fact that a high level of TNF- $\alpha$, and hence, of inflammation, is responsible for its deleterious effect on redox imbalance. The fact that patients without DM has achieved a greater correlation between TNF- $\alpha$ and NOX 4 needs confirmation and explanation. The final levels of hs-CRP were strongly associated with the final expression of NOX4 in the GH group after treatment with this hormone, both decreasing in parallel, which did not occur in the placebo group. Again, the fact that higher CRP levels are associated with greater expression of NOX4 only in the GH-treated group could be explained as a consequence of the significantly higher levels of inflammation in this group.

Baseline level of HbA1C appears to be well correlated with TNF- $\alpha$ in the GH group with DM, supporting the role of this biomarker in patients with high level of inflammation (Figure 7, A). The final levels of HbA1C were inversely related to VEGFA mRNA expression in DM, but only in the placebo group $(r=-0.9747, p=0.0333$ ) (Figure $7, C$ ), which means that untreated DM patients maintain a higher level of inflammation and, therefore, angiogenesis is negatively affected. Thus, $\mathrm{HbA1C}$ should be a possible target in these patients, highlighting the need to a good glycemic control.

On the other hand, mRNA expression of IGF-I seemed to follow an inverse behavior, increasing its expression in ischemic muscles with inflammation, probably as a defense mechanism. This could be consistent with the fact that, in cultures of ECs with a high level of inflammation induced by the addition of CRP, the latter protein increases the phosphorylation of eNOS, decreasing its activity. When IGF-I is added to a medium rich in CRP, the activity of eNOS increases [41], which means that IGF-I exerts a negative feedback on the pernicious effect of CRP on these cells, and that ECs can produce IGF-I in response to a high level of CRP. In our trial, the treatment with GH restores inflammatory and redox imbalances and the association between CRP and IGF-I returns to be inverse (Table 3). In the placebo group, this benefit does not appear, maintaining the positive association. Although CRP and IGF-I have been investigated in PAD-CLTI patients in a prior study [43], only the plasma level of these factors was studied and not the gene expression in the ischemic muscle.

The findings obtained in TNF- $\alpha$ need to be analyzed in depth. This cytokine, together with IL-6, has been shown to be a predictor of future CV events in the healthy population $[16,20]$. The use of TNF- $\alpha$ inhibitors in patients with a high level of inflammation, such as rheumatoid arthritis, decreased atherosclerotic CV events similarly to the use of IL-6 blockers [44], also improving the endothelial dysfunction [24]. One of the most important data obtained in our study is the link between the plasma levels of TNF- $\alpha$ and NOS3 expression. As previously published, NOS3 is one of the most important enzymes that maintains vascular homeostasis and is involved in vascular defense against chronic or excessive inflammation $[26,27]$. TNF- $\alpha$ can affect the activity of NOS3 with an independent action on its gene promoter in a dose- and time-dependent manner [40]. This proinflammatory molecule facilitates the phosphorylation of NOS3, reducing the level of nitric oxide (NO), facilitating endothelial dysfunction and altering the regeneration process $[40,45]$. This finding in humans suggests that TNF- $\alpha$ might be an accurate target for CLTI. To see the importance of the decrease in plasma TNF- $\alpha$ by GH, it is worth highlighting a 
meta-analysis of 54 prospective cohort studies on inflammation and PAD, in which plasma TNF- $\alpha$ was able to predict the risk of CV events with the same magnitude as the therapies for lowering blood pressure or lipids $[46,47]$.

The observation that plasma TNF- $\alpha$ and NOX4 expression run in parallel is also remarkable. NOX4 is the main isoform of NADPH oxidase responsible for TNF- $\alpha$-induced oxidative distress and apoptosis of different cells in the body [48-50]. An important source of ROS in blood vessels comes from NOX catalytic enzymes, which are ubiquitously distributed in the three vessel layers. NOX4, which maintains a physiological basal ROS generation, is highly expressed in cells under stress [26]. NOX4 could play a fundamental role in the regulation of angiogenic growth factors such as VEGFA, since the inhibition of NOX and/or the production of mitochondrial ROS decreases the expression of this growth factor [51]. Thus, it makes sense our finding of the link between TNF- $\alpha$ and VEGFA at baseline in those patients with a high level of inflammation (GH group). Although TNF$\alpha$ can favor vascular homeostasis when is produced in small concentrations by ECs, chronically high production of this particle determines deleterious effects, overstimulating NOX4, which eventually leads to an excess of ROS that ends up in the final inactivation of NO [22,52]. These circumstances warranted ECs activation, favoring the prothrombotic state and thrombotic complications associated with advanced PAD $[28,53]$.

While in the CANTOS study the relevant role is for IL-6 in patients with ischemic heart disease [20], Gardner et al. demonstrated that, in patients with PAD, TNF- $\alpha$ and IL8 levels, but not IL-6, were increased [22], which supports the fact that both diseases seem to show differences in the inflammatory pattern. However, Gardner's study was conducted in patients with intermittent claudication, a less severe form of ischemia with less inflammation, and the causal association between this or other biomarkers and PAD has not yet been established. In the GHAS trial, IL-6 mRNA expression was not altered at baseline and GH treatment did not affect this expression either. However, information on plasma IL-6 levels was not included in the GHAS study.

Another interesting finding is about the angiogenesis marker KDR. An increase in KDR by GH was reported by our group [27]. Now, after stratification, we have found that this increase was mainly happening in patients with DM (Figure 3, C). The final achieved gene expression of this marker was age-dependent. In addition to this relationship between gene expression and a clinical variable, the relationship between final NOS3 expression and wound healing and between final NOX4 expression and Rutherford ischemia class should also be noted (Figure 11).

Last but not least, we have obtained relevant data on some plasma biomarkers and mortality. NLR has been proposed as a marker of adverse complications in CV disease, malignancy, and infection [54]. In PAD, NLR has been incorporated into the ERICVA score for the prediction of poor prognosis in patients with CLTI [55]. The rationale for using this ratio derives from the fact that, on one side, inflammation is frequently associated with neutrophilia, facilitating atherosclerotic plaque rupture and hypercoagulability associated with any ischemic injury [56]. On the other side, lymphocytopenia can be explained because ischemic stress leads to the release of cortisol and catecholamines with neuroendocrine consequences, including a decrease and dysfunction of the lymphocyte count $[56,57]$. In our study we have seen that NLR $\geq 3$ at baseline was related to cumulative mortality at 12 months (Figure 9, A) and was correlated with the level of plasma hs-CRP (Figure 10). Although the appropriate cut-off point for NLR in CV disease has yet to be adequately defined [25], we have found that a value of 3.4 was the best predictor for longterm mortality in CLTI patients (Figure 9, B) with a good sensitivity and specificity and a light to moderate power of the test. This observed value was very close to the average NLR value in the series (3.5). Perhaps, in studies with acute limb ischemia, where NLR is normally higher, the threshold seems to be 5.4 [54], and in those studies including patients mainly with intermittent claudication, who suffer a lower inflammation level, the cut-off point was 5 [55]. It makes sense that the higher the level of inflammation, the lower the NLR cut-off point could be for predicting mortality, and that this cut-off point might be different depending on the morbid condition and the level of inflammation of the same. TNF- $\alpha \geq 8.1$ was also found as a possible predictor of mortality. The calculation of the 
confidence interval for the odds ratio of both biomarkers did not find significant differences (see CI in Table 5), probably as a consequence of the small sample size. This was enhanced by the finding of a low to moderate statistical power for both biomarkers. However, in the case of NLR, it can be seen a clear trend.

The main limitation of the GHAS trial is the relatively small sample size and the lack of confirmation of some of these data (with some exceptions) when a multivariate model was used for statistics, although the latter was only applied to cross-link clinical and plasma variables, not for gene expression. Furthermore, as this study represents the first clinical trial exploring the use of GH for angiogenesis, the dose and time of application of this hormone have not properly been established. As is known, both aspects, dose and time, influence the hormonal benefit $[27,28]$. However, plasma and gene expression data at baseline are not affected by the intervention in this study. The main advantage of this study is that the ischemic muscle has been studied in depth, offering relevant data.

\section{Conclusions}

Vascular homeostasis and redox balance govern vascular health or disease states. Chronic limb-threatening ischemia carries out a high level of inflammation and mortality rate, and seems to show differences in the inflammatory pattern compared to ischemic heart disease. Plasma TNF- $\alpha$ plays a crucial role in both inflammation-mediated redox distress and endothelial dysfunction and regeneration, affecting NOS3 and VEFGA. hsCRP seems to play a more active role that previously assigned, affecting also redox balance and angiogenesis. $\mathrm{HbA} 1 \mathrm{C}$ is a biomarker that needs to be properly studied beyond the glycemic control in diabetic patients. Muscle NOX4 has been revealed key for redox imbalance, and IGF-I expressed in the ischemic muscle increases as a mechanism of defense. Diabetic patients are a especial target population for $\mathrm{GH}$ therapy, as could be inferred from the increase in KDR and the decrease in TNF- $\alpha$ and NOX4 when treated with the hormone. NLR $\geq 3$, together with plasma TNF- $\alpha \geq 8.1$, have been found a good predictor of mortality in the mentioned morbid condition.

All these findings are clinically relevant and open new paths in the search for new drugs to decrease cardiovascular events and to relieve symptoms in patients with advanced lower limb ischemia. Our results are novel because they represent the connection between plasma and muscle gene expression in humans with limb ischemia, and should be corroborated in a larger clinical trial.

Author Contributions: Conceptualization, D.C. and J.D.; methodology, D.C., C.V.A. and S.P.; software, S.P. and D.C; validation, D.C, C.V.A. and J.D.; formal analysis, D.C and S.P; investigation, D.C, C.V.A. and S.P; resources, D.C and C.V.A; data curation, D.C. and S.P; writing-original draft preparation, D.C; writing - review and editing, D.C, C.V.A, S.P and J.D; visualization, D.C. and S.P; supervision, C.V.A and J.D.; project administration, D.C.; funding acquisition, D.C. All authors have read and agreed to the published version of the manuscript.

Funding: The GHAS trial was funded by the Carlos III Health Institute and the European Regional Development Fund (ISCIII- FEDER), Madrid, Spain. Grant number PI 13-00790. CVA is funded by the Agencia Estatal de Investigación (AEI), grant number PID2019-110437RB-I00.

Institutional Review Board Statement: The study was conducted according to the guidelines of the Declaration of Helsinki and approved by the Spanish Agency of Drugs and Health Products (AEMPs) with Eudract number 2012-002228-34, and the Autonomic Committee on Research Ethics in Galicia (CAEIG, 2012/378), Spain. The GHAS trial counts with the registration in the Spanish Registry of Clinical Trials (REEC): 2012-002228-34.

Informed Consent Statement: Informed consent was obtained from all subjects involved in the study.

Acknowledgments: We thank Santiago Pérez Cachafeiro for providing an important stimulus to develop this review and the GHAS trial. Without his help and expertise this article would not have been possible.

Conflicts of Interest: The authors declare no conflict of interest. The funders had no role in the design of the study; in the collection, analyses, or interpretation of data; in the writing of the manuscript, or in the decision to publish the results. 


\section{References}

(1) Heart Protection Study Collaborative Group. MRC/BHF Heart Protection Study of Cholesterol Lowering with Simvastatin in 20536 High-Risk Individuals: A Randomised Placebo-controlled Trial. Lancet 2002, 360 (9326), 7-22. https://doi.org/10.1016/S0140-6736(02)09327-3.

(2) Kumbhani, D. J.; Steg, G.; Cannon, C. P.; Eagle, K. A.; Smith, S. C.; Goto, S.; Magnus Ohman, E.; Elbez, Y.; Sritara, P.; Baumgartner, I.; et al. Statin Therapy and Long-Term Adverse Limb Outcomes in Patients with Peripheral Artery Disease: Insights from the REACH Registry. Eur. Heart J. 2014. https://doi.org/10.1093/eurheartj/ehu080.

(3) Ohman, E. M.; Bhatt, D. L.; Steg, P. G.; Goto, S.; Hirsch, A. T.; Liau, C. S.; Mas, J. L.; Richard, A. J.; Röther, J.; Wilson, P. W. F. The REduction of Atherothrombosis for Continued Health (REACH) Registry: An Interna-tional, Prospective, Observational Investigation in Subjects at Risk for Atherothrombotic Events-Study De-sign. Am. Heart J. 2006. https://doi.org/10.1016/j.ahj.2005.11.004.

(4) Haugen, S.; Casserly, I. P.; Regensteiner, J. G.; Hiatt, W. R. Risk Assessment in the Patient with Established Peripheral Arterial Disease. Vasc. Med. 2007, 12 (4), 343-350. https://doi.org/10.1177/1358863X07083278.

(5) Diehm, C. Association of Low Ankle Brachial Index with High Mortality in Primary Care. Eur. Heart J. 2006, 27 (14), 1743-1749. https://doi.org/10.1093/eurheartj/ehl092.

(6) Resnick, H. E.; Lindsay, R. S.; McDermott, M. M.; Devereux, R. B.; Jones, K. L.; Fabsitz, R. R.; Howard, B. V. Relationship of High and Low Ankle Brachial Index to All-Cause and Cardiovascular Disease Mortality: The Strong Heart Study. Circulation 2004, 109 (6), 733-739. https://doi.org/10.1161/01.CIR.0000112642.63927.54.

(7) Kistorp, C. Risk Stratification in Secondary Prevention. Circulation 2006, 114 (3), 184-186. https://doi.org/10.1161/CIRCULATIONAHA.106.639732.

(8) Brevetti, G.; Giugliano, G.; Brevetti, L.; Hiatt, W. R. Inflammation in Peripheral Artery Disease. Circulation 2010, 122 (18), 1862-1875. https://doi.org/10.1161/CIRCULATIONAHA.109.918417.

(9) Saenz-Pipaon, G.; Martinez-Aguilar, E.; Orbe, J.; González Miqueo, A.; Fernandez-Alonso, L.; Paramo, J. A.; Roncal, C. The Role of Circulating Biomarkers in Peripheral Arterial Disease. Int. J. Mol. Sci. 2021, 22 (7), 3601. https://doi.org/10.3390/ijms22073601.

(10) Aboyans, V.; Criqui, M. H. Can We Improve Cardiovascular Risk Prediction beyond Risk Equations in the Physician's Office? J. Clin. Epidemiol. 2006, 59 (6), 547-558. https://doi.org/10.1016/j.jclinepi.2005.11.002.

(11) Steering Committee of the Physicians' Health Study Research Group. Physicians' Health Study: Aspirin and Primary Prevention of Coronary Heart Disease. N. Engl. J. Med. 1989, 321 (26), 1825-1828. https://doi.org/10.1056/NEJM198912283212610.

(12) Steering Committee of the Physicians' Health Study Research Group. Final Report on the Aspirin Compo-nent of the Ongoing Physicians' Health Study. N. Engl. J. Med. 1989, 321 (3), 129 135. https://doi.org/10.1056/NEJM198907203210301.

(13) Ridker, P. M.; Hennekens, C. H.; Buring, J. E.; Rifai, N. C-Reactive Protein and Other Markers of Inflamma-tion in the Prediction of Cardiovascular Disease in Women. N. Engl. J. Med. 2000, 342 (12), 836-843. https://doi.org/10.1056/NEJM200003233421202.

(14) Kleemann, R.; Zadelaar, S.; Kooistra, T. Cytokines and Atherosclerosis: A Comprehensive Review of Studies in Mice. Cardiovasc. Res. 2008, 79 (3), 360-376. https://doi.org/10.1093/cvr/cvn120.

(15) Ridker, P. M. Anticytokine Agents Targeting Interleukin Signaling Pathways for the Treatment of Athero-thrombosis. Circ. Res. 2019, 124 (3), 437-450. https://doi.org/10.1161/CIRCRESAHA.118.313129.

(16) Kaptoge, S.; Seshasai, S. R. K.; Gao, P.; Freitag, D. F.; Butterworth, A. S.; Borglykke, A.; Di Angelantonio, E.; Gudnason, V.; Rumley, A.; Lowe, G. D. O.; et al. Inflammatory Cytokines and Risk of Coronary Heart Disease: New Prospective Study and Updated Meta-Analysis. Eur. Heart J. 2014, 35 (9), 578-589. https://doi.org/10.1093/eurheartj/eht367.

(17) Sarwar N, Butterworth AS, F. D.; Collaboration), et al (IL6R G. C. E. R. F. Interleukin-6 Receptor Pathways in Coronary Heart Disease: A Collaborative Meta-Analysis of 82 Studies. Lancet 2012, 379 (9822), 1205-1213. https://doi.org/10.1016/S0140-6736(11)61931-4.

(18) Swerdlow DI, Holmes MV, Kuchenbaecker KB; Consortium), et al (IL6R M. A. The Interleukin-6 Receptor as a Target for Prevention of Coronary Heart Disease: A Mendelian 
Randomisation Analysis. Lancet 2012, 379 (9822), 1214-1224. https://doi.org/10.1016/S01406736(12)60110-X.

(19) Qasim, A. N.; Reilly, M. P. Genetics of Atherosclerotic Cardiovascular Disease. In Emery and Rimoin's Princi-ples and Practice of Medical Genetics; Elsevier, 2013; pp 1-37. https://doi.org/10.1016/B978-0-12-383834-6.00061-6.

(20) Ridker, P. M.; Everett, B. M.; Thuren, T.; MacFadyen, J. G.; Chang, W. H.; Ballantyne, C.; Fonseca, F.; Nico-lau, J.; Koenig, W.; Anker, S. D.; et al. Antiinflammatory Therapy with Canakinumab for Atherosclerotic Disease. N. Engl. J. Med. 2017, 377 (12), 1119-1131. https://doi.org/10.1056/NEJMoa1707914.

(21) Signorelli, S. S.; Anzaldi, M.; Libra, M.; Navolanic, P. M.; Malaponte, G.; Mangano, K.; Quattrocchi, C.; Di Marco, R.; Fiore, V.; Neri, S. Plasma Levels of Inflammatory Biomarkers in Peripheral Arterial Disease. An-giology 2016, $67 \quad$ (9), 870-874. https://doi.org/10.1177/0003319716633339.

(22) Gardner, A. W.; Parker, D. E.; Montgomery, P. S.; Sosnowska, D.; Casanegra, A. I.; Esponda, O. L.; Ungva-ri, Z.; Csiszar, A.; Sonntag, W. E. Impaired Vascular Endothelial Growth Factor A and Inflammation in Pa-tients With Peripheral Artery Disease. Angiology 2014, 165 (8), 683-690. https://doi.org/10.1038/jid.2014.371.

(23) Brandt, C.; Pedersen, B. K. The Role of Exercise-Induced Myokines in Muscle Homeostasis and the Defense against Chronic Diseases. J. Biomed. Biotechnol. 2010, 2010, 1-6. https://doi.org/10.1155/2010/520258.

(24) Barnabe, C.; Martin, B.-J.; Ghali, W. A. Systematic Review and Meta-Analysis: Anti-Tumor Necrosis Factor $\alpha$ Therapy and Cardiovascular Events in Rheumatoid Arthritis. Arthritis Care Res. (Hoboken). 2011, 63 (4), 522-529. https://doi.org/10.1002/acr.20371.

(25) Paquissi, F. The Role of Inflammation in Cardiovascular Diseases: The Predictive Value of Neutrophil-Lymphocyte Ratio as a Marker in Peripheral Arterial Disease. Ther. Clin. Risk Manag. 2016, 12, 851. https://doi.org/10.2147/TCRM.S107635.

(26) Bir, S. C.; Kolluru, G. K.; Fang, K.; Kevil, C. G. Redox Balance Dynamically Regulates Vascular Growth and Remodeling. Semin. Cell Dev. Biol. 2012, 23 (7), 745-757. https://doi.org/10.1016/j.semcdb.2012.05.003.

(27) Caicedo, D.; Devesa, P.; Alvarez, C. V.; Devesa, J. Why Should Growth Hormone (GH) Be Considered a Promising Therapeutic Agent for Arteriogenesis? Insights from the GHAS Trial. Cells 2020, 9 (4), 807. https://doi.org/10.3390/cells9040807.

(28) Caicedo, D.; Díaz, O.; Devesa, P.; Devesa, J. Growth Hormone (GH) and Cardiovascular System. Int. J. Mol. Sci. 2018, 19 (1), 290. https://doi.org/10.3390/ijms19010290.

(29) Caicedo, D.; Devesa, J. Growth Hormone (GH) and Wound Healing. Wound Heal. - Curr. Perspect. 2019, No. December. https://doi.org/10.5772/intechopen.80978.

(30) Conte, M. S.; Bradbury, A. W.; Kolh, P.; White, J. V.; Dick, F.; Fitridge, R.; Mills, J. L.; Ricco, J. B.; Suresh, K. R.; Murad, M. H.; et al. Global Vascular Guidelines on the Management of Chronic Limb-Threatening Is-chemia. Eur. J. Vasc. Endovasc. Surg. 2019, 58 (1), S1-S109.e33. https://doi.org/10.1016/j.ejvs.2019.05.006.

(31) Aboyans, V.; Ricco, J.-B.; Bartelink, M.-L. E. L.; Björck, M.; Brodmann, M.; Cohnert, T.; Collet, J.-P.; Czerny, M.; De Carlo, M.; Debus, S.; et al. 2017 ESC Guidelines on the Diagnosis and Treatment of Peripheral Arte-rial Diseases, in Collaboration with the European Society for Vascular Surgery (ESVS). Eur. J. Vasc. Endovasc. Surg. 2018, 55 (3), 305-368. https://doi.org/10.1016/j.ejvs.2017.07.018.

(32) Suárez, C.; Lozano, F.; coordinadores: Bellmunt S, C. M. D. S. M. J. C. E. L. J. Guía Española de Consenso Mul-tidisciplinar En Enfermedad Arterial Periférica de Extremidades Inferiores, 1o ed.; Luzán S.A., Ed.; Madrid, 2012.

(33) Garcia-Rendueles, A. R.; Rodrigues, J. S.; Garcia-Rendueles, M. E. R.; Suarez-Fariña, M.; PerezRomero, S.; Barreiro, F.; Bernabeu, I.; Rodriguez-Garcia, J.; Fugazzola, L.; Sakai, T.; et al. Rewiring of the Apoptotic TGF- $\beta$-SMAD/NFkB Pathway through an Oncogenic Function of P27 in Human Papillary Thyroid Cancer. Oncogene 2017, 36 (5), 652-666. https://doi.org/10.1038/onc.2016.233.

(34) Chenlo, M.; Rodriguez-Gomez, I. A.; Serramito, R.; Garcia-Rendueles, A. R.; Villar-Taibo, R.; Fernandez-Rodriguez, E.; Perez-Romero, S.; Suarez-Fariña, M.; Garcia-Allut, A.; Cabezas-Agricola, J. M.; et al. Un-masking a New Prognostic Marker and Therapeutic Target from the GDNFRET/PIT1/P14ARF/P53 Pathway in Acromegaly. EBioMedicine 2019, 43, 537-552. https://doi.org/10.1016/j.ebiom.2019.04.007. 
(35) Mach, F.; Baigent, C.; Catapano, A. L.; Koskinas, K. C.; Casula, M.; Badimon, L.; Chapman, M. J.; De Back-er, G. G.; Delgado, V.; Ference, B. A.; et al. 2019 ESC/EAS Guidelines for the Management of Dyslipidaemi-as: Lipid Modification to Reduce Cardiovascular Risk. Eur. Heart J. 2019, 1-78. https://doi.org/10.1093/eurheartj/ehz455.

(36) Carlson, B. M. Part.II.Developmento of the Body Systems. Cardiovascular System. In Human Embryology and Developmental Biology; Carlson, B., Ed.; Elsevier: St Louis, Missouri, 2019; p 496. https://doi.org/10.1016/B978-0-12-801238-3.07822-3.

(37) Byrd, N.; Grabel, L. Hedgehog Signaling in Murine Vasculogenesis and Angiogenesis. Trends Cardiovasc. Med. 2004, 14 (8), 308-313. https://doi.org/10.1016/j.tcm.2004.09.003.

(38) Criqui, M. H.; McClelland, R. L.; McDermott, M. M.; Allison, M. A.; Blumenthal, R. S.; Aboyans, V.; Ix, J. H.; Burke, G. L.; Liu, K.; Shea, S. The Ankle-Brachial Index and Incident Cardiovascular Events in the MESA (Multi-Ethnic Study of Atherosclerosis). J. Am. Coll. Cardiol. 2010, 56 (18), 1506-1512. https://doi.org/10.1016/j.jacc.2010.04.060.

(39) Fragoso, J.; Sierra, M.; Vargas, G.; Barrios, A.; Ramírez, J. El Factor de Necrosis Tumoral $\alpha$ (TNF- $\alpha$ ) En Las Enfermedades Cardiovasculares: Biología Molecular y Genética. Gac. Med. Mex. $2013,149,521-530$.

(40) Anderson, H. D. I.; Rahmutula, D.; Gardner, D. G. Tumor Necrosis Factor- $\alpha$ Inhibits Endothelial Nitric-Oxide Synthase Gene Promoter Activity in Bovine Aortic Endothelial Cells. J. Biol. Chem. 2004, 279 (2), 963-969. https://doi.org/10.1074/jbc.M309552200.

(41) Liu, S.-J.; Zhong, Y.; You, X.-Y.; Liu, W.-H.; Li, A.-Q.; Liu, S.-M. Insulin-like Growth Factor 1 Opposes the Effects of C-Reactive Protein on Endothelial Cell Activation. Mol. Cell. Biochem. 2014, 385 (1-2), 199-205. https://doi.org/10.1007/s11010-013-1828-y.

(42) Åberg, N. D.; Wall, A.; Anger, O.; Jood, K.; Andreasson, U.; Blennow, K.; Zetterberg, H.; Isgaard, J.; Jern, C.; Svensson, J. Circulating Levels of Vascular Endothelial Growth Factor and PostStroke Long-Term Func-tional Outcome. Acta Neurol. Scand. 2020, 141 (5), 405-414. https://doi.org/10.1111/ane.13219.

(43) Brevetti, G.; Colao, A.; Schiano, V.; Pivonello, R.; Laurenzano, E.; Di Somma, C.; Lombardi, G.; Chiariello, M. IGF System and Peripheral Arterial Disease: Relationship with Disease Severity and Inflammatory Status of the Affected Limb. Clin. Endocrinol. (Oxf). 2008, 69 (6), 894-900. https://doi.org/10.1111/j.1365-2265.2008.03269.x.

(44) Giles, J. T.; Sattar, N.; Gabriel, S.; Ridker, P. M.; Gay, S.; Warne, C.; Musselman, D.; Brockwell, L.; Shittu, E.; Klearman, M.; et al. Cardiovascular Safety of Tocilizumab Versus Etanercept in Rheumatoid Arthritis: A Randomized Controlled Trial. Arthritis Rheumatol. 2020, 72 (1), 31-40. https://doi.org/10.1002/art.41095.

(45) Yan, G.; You, B.; Chen, S.-P.; Liao, J. K.; Sun, J. Tumor Necrosis Factor- $\alpha$ Downregulates Endothelial Nitric Oxide Synthase MRNA Stability via Translation Elongation Factor 1- $\alpha$ 1. Circ. Res. 2008, 103 (6), 591-597. https://doi.org/10.1161/CIRCRESAHA.108.173963.

(46) Kaptoge, S.; Di Angelantonio, E.; Lowe, G.; Pepys, M. B.; Thompson, S. G.; Collins, R.; Danesh, J.; Tipping, R. W.; Ford, C. E.; Pressel, S. L.; et al. C-Reactive Protein Concentration and Risk of Coronary Heart Disease, Stroke, and Mortality: An Individual Participant Meta-Analysis. Lancet 2010, 375 (9709), 132-140. https://doi.org/10.1016/S0140-6736(09)61717-7.

(47) McDermott, M. M.; Guralnik, J. M.; Corsi, A.; Albay, M.; Macchi, C.; Bandinelli, S.; Ferrucci, L. Patterns of Inflammation Associated with Peripheral Arterial Disease: The InCHIANTI Study. Am. Heart J. 2005, 150 (2), 276-281. https://doi.org/10.1016/j.ahj.2004.09.032.

(48) Basuroy, S.; Tcheranova, D.; Bhattacharya, S.; Leffler, C. W.; Parfenova, H. Nox4 NADPH Oxidase-Derived Reactive Oxygen Species, via Endogenous Carbon Monoxide, Promote Survival of Brain Endothelial Cells during TNF- $\alpha$-Induced Apoptosis. Am. J. Physiol. Cell Physiol. 2011, 300 (2), C256-65. https://doi.org/10.1152/ajpcell.00272.2010.

(49) Moe, K. T.; Yin, N. O.; Naylynn, T. M.; Khairunnisa, K.; Wutyi, M. A.; Gu, Y.; Atan, M. S. M.; Wong, M. C.; Koh, T. H.; Wong, P. Nox2 and Nox4 Mediate Tumour Necrosis Factor- $\alpha$-Induced Ventricular Remodel-ling in Mice. J. Cell. Mol. Med. 2011, 15 (12), 2601-2613. https://doi.org/10.1111/j.1582-4934.2011.01261.x.

(50) Moe, K. T.; Aulia, S.; Jiang, F.; Chua, Y. L.; Koh, T. H.; Wong, M. C.; Dusting, G. J. Differential Upregula-tion of Nox Homologues of NADPH Oxidase by Tumor Necrosis Factor-Alpha in Human Aortic Smooth Mus-cle and Embryonic Kidney Cells. J. Cell. Mol. Med. 10 (1), 231-239. https://doi.org/10.1111/j.1582-4934.2006.tb00304.x. 
(51) Xia, C.; Meng, Q.; Liu, L.-Z.; Rojanasakul, Y.; Wang, X.-R.; Jiang, B.-H. Reactive Oxygen Species Regulate Angiogenesis and Tumor Growth through Vascular Endothelial Growth Factor. Cancer Res. 2007, 67 (22), 10823-10830. https://doi.org/10.1158/0008-5472.CAN-07-0783.

(52) Maekawa, Y.; Ishikawa, K.; Yasuda, O.; Oguro, R.; Hanasaki, H.; Kida, I.; Takemura, Y.; Ohishi, M.; Katsu-ya, T.; Rakugi, H. Klotho Suppresses TNF-Alpha-Induced Expression of Adhesion Molecules in the Endothe-lium and Attenuates NF-KappaB Activation. Endocrine 2009, 35 (3), 341 346. https://doi.org/10.1007/s12020-009-9181-3.

(53) Signorelli, S.; Marino, E.; Scuto, S. Inflammation and Peripheral Arterial Disease. J 2019, 2 (2), 142-151. https://doi.org/10.3390/j2020012.

(54) Coelho, N. H.; Coelho, A.; Augusto, R.; Semião, C.; Peixoto, J.; Fernandes, L.; Martins, V.; Canedo, A.; Gregório, T. Pre-Operative Neutrophil to Lymphocyte Ratio Is Associated With 30 Day Death or Amputation After Revascularisation for Acute Limb Ischaemia. Eur. J. Vasc. Endovasc. Surg. 2021. https://doi.org/10.1016/j.ejvs.2021.03.011.

(55) Brizuela Sanz, J. A.; González Fajardo, J. A.; Taylor, J. H.; Río Solá, L.; Muñoz Moreno, M. F.; Vaquero Puer-ta, C. Design of a New Risk Score in Critical Limb Ischaemia: The ERICVA Model. Eur. J. Vasc. Endovasc. Surg. 2016, 51 (1), 90-99. https://doi.org/10.1016/j.ejvs.2015.09.025.

(56) Madjid, M.; Awan, I.; Willerson, J. T.; Casscells, S. W. Leukocyte Count and Coronary Heart Disease. J. Am. Coll. Cardiol. 2004, 44 (10), 1945-1956. https://doi.org/10.1016/j.jacc.2004.07.056.

(57) Simon, F.; Oberhuber, A.; Floros, N.; Busch, A.; Wagenhäuser, M.; Schelzig, H.; Duran, M. Acute Limb Ischemia-Much More Than Just a Lack of Oxygen. Int. J. Mol. Sci. 2018, 19 (2), 374. https://doi.org/10.3390/ijms19020374. 